Revista de Estudios Histórico-Jurídicos

[Sección historia del derecho canónico]

XLIII (Valparaíso, Chile, 2021)

[pp. 203-237]

\title{
LA CODIFICACIÓN DE 1917 Y LA CANONÍSTICA ESPAÑOLA A TRAVÉS DE LA MANUALÍSTICA Y DE LAS REVISTAS ESPECIALIZADAS*
}

[The 1917 code of canon law and spanish canon law study through manuals and specialized journals]

\author{
Joaquín SEDANO** \\ Universidad de Navarra, España
}

\begin{abstract}
RESUMEN
El presente artículo presenta una panorámica de las posiciones que mantuvo la canonística española en relación con la Codificación canónica de 1917 en los decenios que precedieron y siguieron la promulgación del Código de Derecho Canónico. La orientación metodológica es principalmente bibliográfica: desde el conocimiento que aportan los libros de texto y otras obras especializadas publicadas en España, así como los artículos en revistas científicas y eclesiásticas escritos por autores españoles. Esto ha permitido elaborar un elenco de los principales manuales y libros de texto utilizados en la enseñanza universitaria del derecho canónico y para la praxis jurídica de esos años. Se ha prestado también atención a la biográfica básica
\end{abstract}

ABStRACT

* El presente artículo reproduce algunos de los apartados expuestos en mi conferencia " $I$ giuristi spagnoli e il Codex Iuris Canonici", durante el Convegno di studi "Sistematica e tecnica nelle codificazioni canoniche del XX secolo", organizado por la Facoltà di Diritto Canonico San Pio X de Venecia, durante los días 5 y 6 de mayo de 2017.

** Profesor agregado, Facultad de Derecho Canónico, Universidad de Navarra, Campus Universitario. 31009 Pamplona. Navarra (España). ORCID ID: 0000-0002-7116-987X. Dirección electrónica: jsedano@unav.es 
de la mayoría de los autores presentados, señalando su afiliación a las instituciones educativas donde se formaron e impartieron su docencia o desarrollaron su actividad canónica. Para completar el cuadro, se ofrece también una breve relación de los españoles que participaron en los trabajos de la codificación.

\section{Palabras clave}

Codificación canónica - Código de Derecho Canónico de 1917 - canonística española-manuales - revistas eclesiásticas. where they studied and taught or developed their activities related to the canon law. Finally, there is a brief recount the work of the Spanish authors that participated in the canon law coding.

\section{KeY WORDS}

Canonical Codification - The 1917 Code of Canon Law - Spanish Canon Law Studies - Manuals - Ecclesiastical Journals.

RECIBIDO el 15 de marzo de 2021 y ACEPTADO el 1 de abril de 2021

\section{INTRODUCCIÓN}

Con el presente trabajo pretendo presentar una panorámica de las posiciones que mantuvo la canonística española en relación con la codificación canónica de 1917 en los decenios que precedieron y siguieron la promulgación del Código de Derecho Canónico. La orientación metodológica ha sido principalmente bibliográfica, es decir, desde el conocimiento que aportan los libros de texto y otras obras especializadas publicadas en España, así como los artículos en revistas científicas y eclesiásticas escritos por autores españoles. En este sentido, esta investigación ha permitido elaborar un elenco de los principales manuales y libros de texto utilizados en la enseñanza universitaria del derecho canónico y para la praxis jurídica de esos años. Por otra parte, no he pretendido abordar la búsqueda y consulta de los archivos personales que puedan pervivir de estos autores, que ayudaría a un mejor conocimiento de la materia.

También me ha parecido oportuno mostrar, aunque solo sea brevemente, la participación de los españoles en los trabajos de la codificación, señalando en su lugar oportuno algunos ámbitos que necesitan de posterior investigación. Me ha parecido también importante ofrecer una información biográfica básica de la mayoría de los autores presentados, señalando su afiliación a las instituciones educativas donde se formaron e impartieron su docencia o desarrollaron su actividad canónica para componer, de este modo, un cuadro más completo de la canonística española de esos años.

Para acotar de algún modo este estudio, he establecido el año 1940 como límite temporal. Hasta esta fecha la bibliografía se enfoca principalmente en una profusa labor de comentarios al Código recién promulgado, mientras que en la de los años posteriores, con la perspectiva que daban los decenios pasados, comienzan los canonistas a hacer observaciones más críticas ${ }^{1}$ y a poner en evidencia las

\footnotetext{
${ }^{1}$ Sobre las consecuencias de la asunción de la técnica codificatoria que estudios recientes han puesto de manifiesto $c f r$. FANTAPPIE, Carlo, Dal paradigma canonistico classico al paradigma
} 
deficiencias sistemáticas del Code $x^{2}$, preparando con ello el ambiente intelectual y científico propicio para la posterior reforma que daría lugar a la promulgación del Código de 1983.

Se podrá observar a lo largo de estas páginas que no he tenido mucho reparo en transcribir numerosos textos, de modo que se tenga un acceso más directo al pensamiento de los autores citados.

\section{OPINIONES SOBRE LA NECESIDAD DE LA REFORMA}

\section{DEL DERECHO CANÓNICO}

La situación de la canonística española durante las primeras décadas del siglo XX no era especialmente destacada. Esto era debido, principalmente, a los numerosos cambios de ordenación universitaria, los condicionamientos políticos y la reorganización de los seminarios a raíz del Concordato de 1851 entre el Estado español y la Santa Sede ${ }^{3}$.

Por otra parte, era unánime la posición de todos los tratadistas y articulistas españoles, en sintonía con los autores de otras naciones, de urgir a la necesaria reforma del derecho canónico. Casi todos los autores de manuales y tratados, para justificar la necesidad de la codificación hacen alusión al estado caótico de la legislación canónica, haciendo un sucinto repaso por las principales fuentes canónicas desde Graciano. La situación del estudio y praxis del derecho canónico es relatada con cierto dramatismo por algunos autores, de modo más comedido por otros, pero todos suelen coincidir en la diagnosis.

Aunque en algunas ocasiones se trate de autores que escribieron con posterioridad al Código de 1917, resulta interesante traer aquí en este momento sus impresiones.

codificatorio, en Baura, Eduardo; Álvarez de las Asturias, Nicolás; Sol, Thierry (a cura di), La codificazione e il diritto nella Chiesa (Milano, 2017), pp. 3-34; FAnTAPpIE, Carlo, Per un cambio di paradigma: diritto canonico, teologia e riforme nella Chiesa (Bologna 2019), pp. 36-71; ÁLVAREZ DE LAS Asturias, Nicolás, Decisión, decisiones y consecuencias de la primera codificación canónica: el caso de la idoneidad para recibir las órdenes sagradas, en Ius Canonicum, 115 (2018), pp. 61-62.

${ }^{2}$ Vid., por ejemplo, Lombardía, Pedro, La sistemática del Codex y su posible adaptación, en Estudios de Deusto, 17 (1961), pp. 213-237.

${ }^{3}$ Sobre estas cuestiones pueden consultarse las siguientes obras y la bibliografía en ellas señalada: DE ECHEVERRíA, Lamberto, L'enseignement et les recherches de Droit canonique en Espagne, en L'Année Canonique, 5 (1957), pp. 125-137; Pérez AlHAma, Juan, El Derecho canónico en la Universidad española, en Ius Canonicum, 4 (1964), pp. 371-412; Pedret Casado, Paulino, La evolución de la enseñanza del derecho canónico en España, en Boletim da Faculdade de Direito da Universidade de Coimbra, 22 (1946), pp. 364-380; NAVARro Valls, Rafael, La enseñanza del derecho canónico en las Facultades de Derecho españolas, en Anuario de Derecho Eclesiástico del Estado, 1 (1985), pp. 55-72; RAYÓN BALLESTEROS, María Concepción, Aproximación a la bistoria de la enseñanza del derecho en nuestro país, en Anuario Jurídico y Económico Escurialense, 43 (2010), pp. 215-236; MANTECón SANCHO, Joaquín, La enseñanza del derecho canónico en las universidades públicas españolas, en Kritische Zeitschrift für überkoonfessionelles Kirchenrecht, 3 (2016) (consultado online: http://www.eumed.net/rev/rcdcp/03/jms. html); Regatillo, Eduardo F., La Enseñanz̧a del derecho canónico, en Él mismo, Cuestiones canónicas de "Sal Terrae". Ordenadas y acomodadas al nuevo código canónico (Santander 1927), I, pp. 8-9. 
Concretamente, Felipe Maroto ${ }^{4}$ identifica las siguientes causas: la gran multitud de leyes existentes y su desorden; el modo inadecuado, impropio e impreciso de publicación de la mayoría de ellas; muchos capítulos de las leyes eclesiásticas en su forma externa y directa se referían a casos particulares; muchas carecían completamente de utilidad, otras se confundían por su excesiva semejanza, muchas repetían lo mismo frecuentemente o no eran, hablando en propiedad, tales leyes; muchas leyes eran opuestas, otras muchas no estaban ya en vigor; el derecho concordatario alteraba el derecho común parcialmente; la gran dificultad de encontrar las leyes por parte de cultivadores del derecho o con cura de almas; la complejidad o difícil aplicación de las leyes, bastantes de las cuales por el cambio de las cosas y los tiempos ya no eran convenientes o eran de difícil o imposible ejecución y observancia; por otra parte, sobre ciertos asuntos nada decían las leyes canónicas y había que acudir al derecho romano o al de cada nación. Maroto acababa este elenco haciendo referencia al ejemplo de las naciones modernas, que habían promulgado sus respectivas codificaciones civiles ${ }^{5}$.

Juan Postíus ${ }^{6}$, por su parte, sintetizaba así la necesidad de la reforma canónica: " $1^{\circ}$ La falta de orden lógico, la inutilidad de muchos documentos, el carácter particular de otros, su silencio en materias importantes, el desuso de otras en fuerza de la costumbre o de los Concordatos, y el cúmulo inmenso de leyes (onus multorum camelorum) hacían imposible el estudio por otra parte necesario del derecho de la Iglesia [...] $2^{\circ}$ Veíase también la necesidad de reformar leyes tan sagradas como los impedimentos matrimoniales y los preceptos de ayunos y abstinencias. $3^{\circ}$ Todos pregonaban la necesidad de la revisión y reforma del Cuerpo Canónico [...] $4^{\circ}$ Los Papas accedieron a la codificación de lo más urgente" ${ }^{\text {. }}$.

Del mismo modo Jaime Torrubiano ${ }^{8}$ : "Era tal la multitud de leyes canónicas

${ }^{4}$ Sus datos biográficos aparecen más abajo, en el epígrafe dedicado a los españoles miembros de la Comisión de consultores para la elaboración del Código canónico.

${ }^{5}$ Maroto, Felipe, Instituciones de derecho canónico de conformidad con el nuevo Código (Madrid, 1919), I, pp. 152-158.

${ }^{6}$ Juan Postíus y Sala (Berga [Barcelona], 8/08/1876 - Solsona [Lleida], 23/08/1952), ingresó en el seminario menor de los misioneros claretianos en Barbastro (Huesca). Fue subdirector, procurador y postulador de su Congregación. Estudió en el Seminario Romano de san Apolinar, donde obtuvo el doctorado in utroque Iure. Director espiritual del seminario de Madrid (1905-1922). Fundó la revista Ilustración del Clero y colaboró también en Iris de Paz. Cfr. AldeA Vaquero, Quintín-Marín Martínez, Tomás-Vives Gatel, José (dirs.), Diccionario de historia eclesiástica de España, Consejo Superior de Investigaciones Científicas (Madrid, 1972-1987), III, p. 2011; Diccionario biográfico español, Real Academia de la Historia (Madrid, 2009-2013), XLII, pp. 132-134; Pujadas, Tomás Luis, El Padre Postius: un hombre para la Iglesia (Barcelona, 1981).

${ }^{7}$ En referencia a las constituciones Apostolicae Sedis -para la unificación de las censuras-, Officiorum -en relación con la censura de libros-, Conditae - para las congregaciones religiosas-y la instrucción de la Sagrada Congregación de Obispos y Religiosos de 11 de junio de 1880 para el procedimiento económico en las causas eclesiásticas: Postíus y SALA, Juan, El Código canónico aplicado a España en forma de Instituciones (5ª ed., Madrid, 1926), pp. 329-330.

${ }^{8}$ Jaime Torrubiano Ripoll (Fondarella [Lleida], 09/12/1879 - Madrid, 03/06/1963), de formación polifacética y figura controvertida en el catolicismo español de la época. En 1895 entra en el noviciado claretiano. Estudia Humanidades, Filosofía y Teología en Santo Domingo de la Calzada, Barbastro y Cervera. Abandona la Congregación en 1904. Conferenciante, articulista, abogado, escritor, traductor del latín, periodista y profesor de ingeniería industrial. Ocupó la 
y tanta su dispersión, que se juzgaba poco menos que imposible el conocimiento de ellas, aun para los habitualmente aplicados a sus fuentes [...] Los obligados a entender en causas eclesiásticas no acertaban en la aplicación del canon correspondiente, agobiados por la incontable multitud de ellos [...] Añádase a la multitud de leyes el desorden con que eran presentadas [...] No eran tampoco pequeñas causas de confusión la forma con que estaban redactadas las leyes, pues la parte dispositiva, que es la ley propia, iba envuelta de parte narrativa, expositiva y aun subjetiva, con gran prolijidad y ampulosidad, y la circunstancia de que muchas leyes se referían a casos particulares; lo cual todo hacía que gran número de ellas hubiesen perdido totalmente su utilidad y otras no fuesen sino repetición de anteriores y frecuentemente se tropezase con casos de verdadera oposición [...] La insuficiencia de los cánones para el régimen de la Iglesia, pues, a pesar de la abrumadora abundancia, nada decían de ciertos asuntos, y era preciso acudir al Derecho civil"'.

En sentido similar, resaltando o añadiendo algún matiz o aspecto, se manifestaban la mayoría de los autores ${ }^{10}$.

Aunque en la identificación de las dificultades y la necesidad de la reforma existía una evidente unanimidad, no sucedía lo mismo a la hora de proponer las soluciones concretas.

Hay dos autores que destacan por su posición fuertemente contraria, e incluso hostil, a la codificación: Cipriano Herce ${ }^{11}$ y Camilo Palau ${ }^{12}$. Ambos escriben en épocas tempranas, tres décadas antes de la codificación.

El primero de ellos parece resentir una fuerte influencia de la Escuela histórica del derecho cuando afirma que "la Codificación así considerada, ofrece un inconveniente mucho más grave que todos los de la Recopilación ${ }^{13}$; a saber: que

cátedra de Derecho matrimonialy familiar de la Academia de Jurisprudencia y Legislación de Madrid. Excomulgado en 1925 por Eijo y Garay, obispo de Madrid, por la publicación de su libro El divorcio vincular y el dogma católico. Defendió el uso del catalán durante la dictadura de Primo de Rivera. En 1947 fue condenado a prisión por su implicación en el intento de restauración de la monarquía en la figura de don Juan de Borbón. Cfr. ArbeloA, Víctor Manuel, Los hombres que se adelantan a su tiempo: Jaime Torrubiano Ripoll (1879-1963), en El Ciervo, 230 (1973), 22, pp. 8-9; Él Mismo, Aquella España católica (Salamanca, 1975), pp. 57-64.

${ }^{9}$ Torrubiano Ripoll, Jaime, Novísimas instituciones de derecho canónico. Acomodadas al nuevo 'Código' ordenado por S. S. el Papa Pio X y promulgado por la Santidad de Benedicto XV (3a ed., Madrid, 1935), I, pp. 5-6.

${ }^{10}$ Una buena síntesis de todos estos elementos se encuentra en AgUilar JimÉnEZ, Juan, El nuevo Código de Derecho Canónico, en Revista Eclesiástica, 40 (1917), pp. 259, 261-265.

${ }^{11}$ Cipriano Herce y Castro nació en Pozoantiguo (Zamora). Estudió en el seminario diocesano de Zamora y en el conciliar san Carlos Borromeo, donde obtuvo los grados de bachiller, licenciado y doctor en Teología. Recibió la ordenación sacerdotal en 1875. En 1881 obtuvo el grado de licenciado en derecho civil y canónico. En 1887 ganó las oposiciones a la magistralía de la catedral de Madrid. Fue prosinodal y visitador de la diócesis de Madrid-Alcalá y catedrático de Patrología y Oratoria sacra en el seminario de dicha diócesis. Cfr. Ramos Pérez, Herminio, Zamoranos de ayery de siempre, (Zamora, 2015). Consultado en: http://www.laopiniondezamora. es/opinion/2009/08/07/cipriano-herce-castro/375947.html

${ }^{12}$ Camilo Palau y Huguet, maestrescuela del cabildo madrileño.

${ }^{13}$ Esto es lo que entiende Herce por compilación: “tener un cuerpo de leyes en el que todo esté perfectamente organizado, en el que cada institución, expuesta con método y claridad, 
el estado social de los hombres, pueblos y naciones no se somete, ni de bueno ni de mal grado, al orden de la lógica; y como el Derecho ha de ser la expresión del orden social en individuos y colectividades, resulta imposible constituirlo, y, por consiguiente, desenvolverlo conforme a lo que reclama el orden riguroso de la lógica"14.

Y más adelante para resaltar las ventajas de la recopilación frente a la codificación: "toda la diferencia consiste en que la Recopilación forma y la Codificación crea: la primera construye con materiales ya labrados, y la segunda va elaborando al paso que los extrae de la cantera [...] La Recopilación determina lo presente por lo pasado; la Codificación prescinde de lo pasado y solo atiende a lo que es; la una es tradicionalista, la otra positivista; aquella, por su propia naturaleza, es conservadora; esta, por la suya, revolucionaria [...] por eso en la Recopilación resplandece la prudencia, al paso que la Codificación peca de audacia ${ }^{15}$. Para concluir que "tratándose $[. .$.$] de Derecho canónico, creemos que son muchas$ las ventajas que ofrece la Recopilación sobre la Codificación. Si los jurisconsultos modernos opinan de otra manera, será sin duda por el virus liberal que inficiona las inteligencias hasta de los hombres ilustres de nuestra época"16.

Herce finaliza su discurso inclinándose a creer que para la reforma del derecho canónico la Iglesia optará por la recopilación, precisamente apoyándose en la petición hecha por treinta y tres padres conciliares del Vaticano ${ }^{17}$. De estas afirmaciones, referidas a la reforma del derecho canónico ${ }^{18}$, se puede deducir que el rechazo de Herce a la codificación se funda en una posición ideológica de principio, sin que las ventajas prácticas de la codificación hagan mella en su firme convicción.

Camilo de Palau también reacciona de modo claro frente a la codificación ${ }^{19}$.

ocupe el lugar que le corresponde, recibiendo la luz que necesita para ser bien entendida de las anteriores, y comunicándosela a las que vayan en pos: una Summa Canonica, en una palabra [...] suprimiendo las leyes anteriores que perdieron todo su vigor, y colocando las nuevas en el tratado que les corresponde, para tener a la mano todo el derecho vigente a fin de aprenderlo con facilidad y de aplicarlo con acierto en los casos particulares que haya que resolver, esto es, repito, el summum desideratum de todos los hombres de ciencia, de los jueces, de los abogados, de los estudiantes, de todos los sacerdotes y de muchos seglares que los están reclamando": Herce, Cipriano, La reforma del derecho canónico, en La Luz Canónica, 1/1 (1891-1892), p. 197.

${ }^{14}$ Ibíd. En la transcripción de los textos he alterado las tildes de palabras para hacerlas coincidir con la ortografía actual.

${ }^{15}$ Ibíd., p. 262.

${ }^{16}$ Ibíd., pp. 263-264.

${ }^{17}$ Cfr. Mansi, Joannes Dominicus (ed.), Sacrorum Conciliorum nova et amplissima collectio (Graz, 1960-1962), LIII, coll. 478-480.

${ }^{18}$ Su escrito se encuentra dividido en varios artículos: La Luz Canónica, $1 / 1$ (1891-1892), pp. 131-135, 193-199, 261-268, 333-337, 454-458. Antes había dedicado unas páginas preliminares sobre cuestiones fundamentales e históricas del derecho canónico en la sección de "Derecho público eclesiástico" de la misma revista: ibíd., pp. 5-14 y 74-79.

${ }^{19}$ Publica su posición en una larga serie de artículos bajo el título El Código civil y el Código eclesiástico: La Luz Canónica, 1 /1 (1891-1892), pp. 100-108, 163-172, 294-313, 348-361, 423-436, 570-584, 632-647, 704-715, 766-777; ibíd., 1.2 (1893), pp. 51-61, 108-117, 173-183, 237-247, 295 303, 363-371, 414-426, 544-551, 624-630, 684-692, 739-751. En estas páginas trata por extenso la formación, contenido, tendencias y autoridad del Código civil y las compilaciones canónicas. 
Tratando de las codificaciones civiles, explica su aparición con las siguientes razones: la homogeneidad del derecho civil debido a la universalización del derecho romano por el renacimiento; la derogación del derecho anterior tras la Revolución francesa; la universalización o vulgarización del derecho, que ha llevado a los profanos al jurado y a la consiguiente exigencia de que las leyes se encuentren compendiadas en códigos de pronta, clara y fácil aplicación; el espíritu de imitación de las sociedades modernas que llevan a copiarse unas a otras ${ }^{20}$.

Palau muestra un evidente desdén por el resultado técnico de la codificación civil española debido a la falta de un estudio y trabajo adecuados ${ }^{21}$, así como un juicio muy negativo sobre la cualidad moral y profesional de una gran parte de los miembros de las Cortes ${ }^{22}$. Para el autor el carácter y tendencias del Código español son patentes: "se procedió atropelladamente a amalgamar leyes e instituciones, codificando un cuerpo legal cuyos orígenes estaban preparados 'por las corrientes de la revolución francesa que invadían a España desde 1810, por el principio individualista proclamado desde el tiempo de los fisiócratas y defendido entre nosotros por los Ministros y Fiscales del Consejo de Carlos III', a la vez que por la abolición de los señorios en 1811, la funesta desamortización dispuesta desde $1820 \mathrm{y}$ el Proyecto de Código civil individualista de 1851, sirviendo de génesis al Código civil actual [...] teniendo por precursores los principios revolucionarios del 93, por esencia un individualismo egoista o un liberalismo disolvente, por fórmula doctrinas de escuelas racionalistas o positivistas, el cesarismo o capricho por ejecutores, y por Padres Cuerpos Colegiados nacidos al calor del influencias de partido, de rencores de banderías o de intrigas de políticos sin conciencia, ni fe, ni ley [...] que demuestran en el Código tendencias materialistas, tendencias penetradas enteramente de un terrible espiritu de secularización [...] Código civil, que, en multitud de artículos, desarrolla instituciones o favorece inmoralidades, destructoras completamente del carácter tradicional de la familia española, de la paz del hogar y de las buenas costumbres [...] Finalmente, resumiendo todo lo dicho hasta ahora relativamente a las tendencias del Código civil español, tenemos que en lo que se refieren al Derecho antiguo o histórico son destructoras de las tradiciones patrias y de los fundamentos jurídicos de nuestra venerada legislación; en lo que mira al Derecho civil son o demasiado atrevidas o demasiado atrasadas, constituyendo un retroceso más bien que un progreso en la ciencia del Derecho con grave daño del individuo, de

${ }^{20}$ Cfr. Ibíd., en La Luz Canónica, 1/1 (1891-1892), pp. 101-102.

21 "Por el modo de formarlo adolece de precipitación [...] falto de estudio [...] y falto de método, evidenciado por publicistas de fama; por su contenido es una mezcla de preceptos viejos con reformas nuevas e instituciones novísimas que son refractarias enteramente al espíritu que informó a los primeros [...] por sus tendencias se ve en él muy claro el principio generador de todas las Constituciones y Códigos modernos, que es la emancipación de la sociedad de todo lo que sea tradicional, consuetudinario y derivado del espíritu cristiano que la Iglesia imprimió a la sociedad civil": ibíd., pp. 106-108.

${ }^{22}$ Opina que la selección de los miembros a las Cortes no es resultado del mérito profesional, sino de los resortes de presión presentes en los ambientes políticos y de gobierno. De ahí resulta "forzosamente leyes y Códigos no inspirados en el bien y en la justicia [...] sino en compromisos políticos y convencionalismos de escuela, en transacciones y componendas de partidos, no siempre honrosas, y muchas veces inicuas o injustas": ibíd., pp. 710-711. 
la familia y de la propiedad, y por lo que se dice a la Moral, sus tendencias son osadas, inmorales, peligrosísimas y dignas de absoluta reprobación"23.

Frente a todos estos aspectos negativos que resalta del Código civil español, Palau dedica ingenuas alabanzas a la compilación canónica, cuando por todos eran conocidas y criticadas las dificultades para el estudio y la praxis que experimentaba la legislación canónica.

Fuera de estos dos autores ${ }^{24}$, las posiciones en relación con la codificación son más moderadas e, incluso, favorables a ella. Muestra de ello es el manual de Andrés Manjón y Manjón ${ }^{25}$ que, aunque en algún pasaje parece abogar por una nueva compilación ("cuantos tratadistas tocan hoy este punto, están conformes en la necesidad de una nueva Colección auténtica"), es claro al afirmar que una nueva colección canónica al estilo del Liber Extra, para añadir al Corpus, no remediaría el caos de la normativa canónica ${ }^{26}$, y que por tanto solo restan dos vías, o la codificación, o una nueva colección con solo el derecho vigente: "Quedan dos medios: el de formar una Compilación concisa y metódica de solo el derecho vigente, y el de codificar (si faltan alientos para todo) por partes, a estilo de lo que se ha hecho en cierto modo, con las penas latae sententiae por la bula Apostolicae Sedis de 1869. Análogos trabajos, aunque en esfera más amplia, pudieran emprenderse respecto al Derecho público fundamental, Jerarquía y Sacramentos, Bienes, Penas

${ }^{23}$ La Luz Canónica, $1 / 1$ (1891-1892), pp. 712-714; La Luz Canónica, 1/2 (1893), pp. 366, 414, 425-426.

${ }^{24}$ Las posiciones de Herce y Palau fueron descritas por DE ECHEVERría, Lamberto, La codificación del derecho canónico vista en España a finales del siglo XX, en Apollinaris, 33 (1960), pp. 327-341.

${ }^{25}$ (Sargentes de la Lora [Burgos], 30/11/1846 - Granada 10/07/1923). Realizó sus estudios de Filosofía en el Seminario de Burgos y la carrera de Derecho en la Universidad de Valladolid. Obtuvo el doctorado en Derecho por la Universidad Central, dio clases de Derecho romano en la Universidad de Salamanca y de Derecho canónico en la Universidad de Valladolid. Obtuvo la cátedra de Disciplina General de la Iglesia y particular de España en la Universidad de Santiago, de allí se trasladó a la cátedra de Instituciones de Derecho canónico de la Universidad de Granada. Continuó sus estudios en el Seminario del cabildo de la Abadía del Sacro Monte, en la misma ciudad, donde fue ordenado sacerdote en 1886. Además de su docencia en la Universidad, dio clases de Derecho canónico en el Seminario de la Abadía, donde recientemente se había creado una Facultad de Derecho canónico. Tradujo al español y anotó la obra de Camillo Tarquini, Instituciones de derecho público eclesiástico seguidas de una disertación sobre el Pase Regio, del Syllabus y la Constitución Pastor Aeternus' del concilio vaticano (Granada, 1881). Cfr. Diccionario de catedráticos españoles de derecho (18471943) [en línea]. Universidad Carlos III de Madrid. Instituto Figuerola de Historia y Ciencias Sociales, 2011-, Disponible en: http://www.uc3m.es/diccionariodecatedraticos; Diccionario de Historia Eclesiástica de España, cit. (n. 6), II, p. 1407; Diccionario Biográfico Español, cit. (n. 6), XXXII, pp. 36-39; Diccionario crítico de juristas españoles, portugueses y latinoamericanos (Hispánicos, brasileños, Quebequenses y restantes francófonos), PeLÁEZ, Manuel J. (ed), (Zaragoza - Barcelona, 2005-2006), II.1, pp. 35-37.

26 "Un trabajo que tenga unidad y sea metódico, sistematizado, claro, sencillo, breve, que contenga solo el derecho vigente, con las reformas necesarias, en el que nada haya que no sea genuino, y quepan los elementos utilizables de todas las fuentes canónicas sin tortura ni confusión, no puede conseguirse con el séptimo indicado": Manjón y Manjón, Andrés, Derecho eclesiástico general y español (4ª ed., Granada, 1913), I, n. 431, p. 167-168. 
y Delitos, Procedimiento civil y penal, o cualquiera de sus partes. Este sistema es fácil, y tiene en su favor tanta o más literatura como el de las Decretales"27.

Como se puede apreciar en las páginas precedentes, los autores coinciden en señalar cuatro posibilidades: compilar una nueva colección para añadir al Corpus Iuris Canonici; realizar una nueva compilación exclusiva del derecho vigente; proceder mediante progresivas codificaciones parciales; o decidirse por una codificación del derecho vigente siguiendo el modelo napoleónico. Manjón y Manjón es partidario, en el caso de que se opte por la codificación, de proceder por partes o secciones, para salvar la dificultad de una codificación completa y simultanea de todo el derecho. Juan Bautista Ferreres ${ }^{28}$ es partidario decidido de una verdadera codificación: "En cuanto a la extensión y forma del nuevo código, parece ser deseo bastante común: $1^{\circ}$ Que se extienda a todo el derecho general hoy vigente [...] $2^{\circ}$ Que no se haga imitando las antiguas colecciones y copiando fragmentos de constituciones pontificias, sino más bien por medio de artículos breves, claros y sencillos, imitando los nuevos Códigos civiles de Europa y América [...] Será también mucho de desear que el orden legal del nuevo Código sea tan lógico que pueda seguirse en las exposiciones de la cátedra y en los tratados didácticos"29.

Ferreres sabe distinguir bien entre las ventajas que podría traer la codificación como instrumento técnico y los principios ideológicos que estaban en el origen de las codificaciones civiles: "Aunque la doctrina de estos códigos modernos no siempre esté de acuerdo con los sanos principios católicos, su forma, no obstante, es digna de singular aprecio, pues facilita grandemente el conocimiento del Derecho y hace más sencilla y segura su aplicación en los tribunales"30. En relación con la cuestión de dejar el código como única fuente legal, Ferreres parece inclinarse en sentido positivo: "El nuevo Código ¿convendrá que deje como fuente legal la parte disciplinar del Tridentino en todo lo que no sea necesario introducir modificación, o será preferible que aun en este punto la única fuente legal sea el mismo Código? Ambos extremos tendrán sus partidarios; pero, a pesar del amor y reverencia que a todos merece aquel santo Concilio, creemos que no todos verían con disgusto que solo el nuevo Código quedara como fuente legal”'31.

También Ramiro Fernández Valbuena ${ }^{32}$ es un firme partidario de la codificación en esa época. Afirma de modo tajante que no "sirven para la época presente las antiguas colecciones canónicas, que respondieron a una urgente necesidad de aquellos tiempos, ni el Decreto de Graciano, que fue un verdadero adelanto a la

${ }^{27}$ Ibíd.

${ }^{28}$ Sus datos biográficos se encuentran señalados más abajo, en el apartado de colaboradores externos para la elaboración del Código.

${ }^{29}$ Ferreres, Juan Bautista, La codificación del derecho canónico decretada por Pio X, en Razón y Fe, 9 (1904), pp. 365 y 368.

${ }^{30}$ Ibíd., p. 368.

${ }^{31}$ Ibíd., p. 369.

${ }^{32}$ (Huelde [León], 14/03/1847 - Santiago de Compostela, 1922). Filólogo, teólogo, historiador y orientalista. Sacerdote incardinado en Badajoz, canónigo penitenciario de Toledo y obispo auxiliar de Santiago de Compostela desde 1911. En 1919 fue elegido Senador por este arzobispado. Cfr. http://www.senado.es/web/conocersenado/senadohistoria/senado18341923/ senadores $/$ fichasenador $/$ index.html?id1 $=1014$ 
Ciencia canónica, ni los Códigos posteriores, que, con valer mucho, no satisfacen a las necesidades presentes" "33. Según él, para obviar las graves dificultades en que se encuentra el estudio y conocimiento del derecho canónico "nada tan a propósito como la codificación" 34 . En este sentido, hace alusión al fenómeno codificatorio de las principales naciones de Europa y América, así como a las iniciativas eclesiales, que él denomina como "ensayos y principios de codificación”, llevadas a cabo mediante el Syllabus y la bula Apostolicae Sedis de Pío IX.

Frente a los autores que rechazan la codificación escribe Fernández Valbuena: "Parécennos poco o nada fundados los temores de aquellos que manifiestan recelos hacia el Código canónico, porque evidentemente éste no ha de adolecer de los defectos graves que afean a nuestro Código civil [...] Ni tampoco el nuevo Código había de ser un rompimiento brusco con el pasado, sino más bien una aplicación de la sabiduría de los tiempos viejos a las necesidades nuevas. Si a esto añadimos que la publicación del Código no ha de implicar la abolición de usos y costumbres laudables y legítimamente introducidas en las varias naciones cristianas [...] concluiremos manifestando nuestros más ardientes deseos de que cuanto antes se ponga manos a la obra y el nuevo Código eclesiástico ilumine las tinieblas de la ciencia jurídica [...] despejando la atmósfera social, saturada de miasmas corruptores procedentes de los impuros manantiales que se llaman protestantismo, naturalismo, racionalismo, regalismo, liberalismo, y tantos otros ismos" 35 .

Fernando Torralba y García de Soria ${ }^{36}$, en una obra poco difundida ${ }^{37}$, apostaba de manera firme y certera por un código, que define como "un sistema completo de Derecho, un conjunto de instituciones jurídicas, un cuerpo orgánico" con "un orden y método rigurosamente lógico y científico". A pesar de coincidir en algunas de las críticas realizadas por Herce y Palau a los principios ideológicos de las codificaciones civiles, que califica de inconvenientes gravísimos, piensa que "la codificación del Derecho canónico no puede nunca tener las dificultades de la codificación civil, porque la pureza y la rectitud de sus principios constitutivos, y la santidad, justicia e imparcialidad de sus leyes, la ponen a cubierto de esos inconvenientes de la codificación en los Estados".

A medida que los trabajos de codificación iban avanzando, el apoyo al sistema de la codificación era más evidente en los diversos autores. Un ejemplo de

\footnotetext{
${ }^{33}$ La Luz Canónica, 2/1 (1899-1900), p. 20.

${ }^{34}$ Ibíd., p. 23.

${ }^{35}$ Ibíd., p. 26.

${ }^{36}$ Presbítero y abogado, doctor en Teología y en Derecho civil y canónico, cura propio de la parroquia mayor de Santa Cruz de Écija, examinador sinodal de la diócesis de Cádiz, examinador del clero diocesano y fiscal general de la archidiócesis de Sevilla y consiliario eclesiástico de la Real Hermandad de Caballeros y Damas de San Fernando. Datos tomados de la obra: Sermón panegírico del Gran Apóstol San Pablo, Patrono de la muy Noble y Muy Leal ciudad de Ecija, predicado el día 25 de enero de 1958, día de su conversión, en la Iglesia de Santo Domingo de la misma ciudad (Écija, 1958).

${ }^{37}$ La codificación del derecho canónico, tesis defendida en la Facultad de Derecho canónico de Madrid y publicada en Sevilla en 1906. Noticia y citas de la obra tomadas de FAnTAPpiè, Carlo, El Código de 1917 en la bistoria del derecho de la Iglesia, en Anuario de Derecho Canónico, 7 (abril 2018), pp. 45-46.
} 
ello es Diego Tortosa ${ }^{38}$ : “¿respondía en la actualidad el Derecho canónico a las circunstancias por las que atraviesa el mundo y a la tradición sapientísima de la Iglesia, de adaptar su legislación a las necesidades de los tiempos? Desde ese doble aspecto, fácil es dar respuesta negativa [...] El Derecho eclesiástico [...] estaba pidiendo en nuestros días urgente reforma. Después de seis siglos, en los que no se hizo obra alguna de codificación universal, el Derecho eclesiástico debía conceder especialísima atención a los elementos modernos, que las trasformaciones sociales e intelectuales han traído a la esfera jurídica [...] Era a la vez preciso que la Iglesia Católica, que predicando la fraternidad entre los hombres creó el Derecho internacional, y [...] fue la primera propulsora de la civilización en el mundo, recogiera en su derecho la evolución de las legislaciones de los pueblos todos, que tiende a la universalidad y al cosmopolitismo" 39 .

En el año 1917, cuando ya era inminente la promulgación del Código de Derecho Canónico, diversos autores pusieron por escrito su perspectiva de la necesidad de la reforma del derecho canónico y de la elección de la codificación como instrumento técnico ${ }^{40}$; pero es evidente que estas posturas estaban ya totalmente condicionadas por la decisión tomada por Pío X y Benedicto XV, como se verá también cuando se pase a comentar la literatura posterior a la promulgación del Código.

\section{PARTicipación ESPAÑOla EN LA CODificACióN}

En el presente epígrafe no se pretende realizar una exposición detallada de la labor realizada por los canonistas españoles en la elaboración del primer Código de Derecho Canónico. Simplemente persigue enriquecer la visión de la canonística española de la época, ofrecida en estas páginas, mediante una sucinta relación de quiénes participaron en las diversas comisiones, sus principales rasgos biográfi$\cos ^{41}$ y los datos que hasta el momento se conocen de su colaboración. Se trata

\footnotetext{
${ }^{38}$ (Cieza [Murcia], 1877 - Madrid, 16/12/1947). Sacerdote. Estudió Ciencias y Derecho en las universidades de Madrid y Barcelona. Doctor en Teología, en Derecho y Derecho canónico, catedrático de los seminarios de San Fulgencio de Murcia y del Conciliar de Madrid, canónigo por oposición de la catedral de Madrid, predicador de honor del rey Alfonso XIII, miembro de la Real de Academia de Jurisprudencia y Legislación de Madrid. Cf. Marín Cano, Alfredo, El Canónigo Dr. D. Diego Tortosa y Nicolás (1877-1947) (Murcia, 2014).

${ }^{39}$ Revista general de legislación y jurisprudencia, 131 (1917), pp. 410-412. Diego Tortosa escribió una serie de artículos en esa misma revista a lo largo de varios años bajo el título de El nuevo código de derecho canónico: cfr. los números 131 (1917), pp. 399-412; 132 (1918), pp. 68-89, 361-379; 133 (1918), pp. 99-117, 239-257; 134 (1919), pp. 15-27; 135 (1919), pp. 110-130; 137 (1920), pp. 116-138; 138 (1921), pp. 309-324.

${ }^{40}$ Cfr. Campos y Pulido, José María, El nuevo Código de Derecho canónico y su próxima publicación, en Revista general de legislación y jurisprudencia, 130 (1917), pp. 374-378; Noval, José, El Código de derecho canónico, en La Ciencia Tomista, 16 (1917), pp. 145-146; VIDAL, Pedro, Il nuovo Codice di diritto canonico, en La Civiltà Cattolica, 68/2 (1917), pp. 545-559 (sus contribuciones siguen en los siguientes números de la revista).

${ }^{41}$ Un excelente elenco de datos biográficos de colaboradores se encuentra en FANTAPPIÈ, Carlo, Chiesa romana e modernità giuridica, II: Il Codex iruis canonici (1917) (Milano, 2008), pp. 1169-1239.
} 
este de un aspecto que ofrece un amplio campo a la investigación posterior. Lo mismo cabe decir de la aportación del episcopado español.

\section{En la Comisión pontificia de cardenales}

Se trata de la comisión a la que se encargó la dirección general de los trabajos preparativos para la codificación. Sus componentes fueron designados directamente por Pío X en un elenco publicado a continuación del m.p. Arduum sane munus $^{42}$. Dos de ellos eran españoles: José Calasanz Vives y Tutó y Rafael Merry del Val. Ambos ya habían participado en la primera reunión de cardenales celebrada el 3 de marzo de $1904^{43}$.

Merry del $\mathrm{Val}^{44}$ fue uno de los tres cardenales de esta comisión, junto con Vannutelli y Cassetta, que vieron finalizada la obra de la codificación. Su implicación en la tarea codificatoria ya se aprecia desde el primer momento al ser él mismo quien, a través del envío de la carta circular Pergratum mibi (25.03.1904), informó al episcopado de rito latino de las modalidades de participación en los trabajos de codificación. Al tratarse de una persona de la más estrecha confianza de Pío $\mathrm{X}$, a día de hoy no es posible conocer, como bien afirma Fantappiè, los encargos de esbozos o partes de libros que pudo haber recibido por parte del pontífice ${ }^{45}$.

El cardenal Vives y Tutó ${ }^{46}$ es considerado como una de las personalidades

${ }^{42}$ Acta Sanctae Sedis, 36 (1903-1904), p. 551.

${ }^{43}$ En esta reunión participaron además los cardenales Serafino Vannutelli, Agliardi, Vincenzo Vannutelli, Rampolla, Gotti, Ferrara, Caseta, Gennari, Cavicchioni, Steinhuber, Segna y Cavagnis, así como Gasparri en su condición de secretario. Eran los mismos nombres propuestos por el cardenal Gennari, a los que se agregaba Merry del Val: cfr. SALINAS ArAnEdA, Carlos, La codificación del derecho canónico de 1917, en Revista de Derecho de la Pontificia Universidad Católica de Valparaiso, 30 (2008), p. 326.

${ }^{44}$ Rafael Merry del Val y Zulueta (Londres, 10/10/1865 - Ciudad del Vaticano, 26/02/1930). Español de nacionalidad, educado en Bélgica, Inglaterra y Roma (Colegio Escocés, Universidad Gregoriana y Academia Pontificia Romana). Secretario del Colegio cardenalicio, Secretario de Estado de la Santa Sede y Prefecto de la Casa pontificia (1903-1914), Secretario de la Congregación del Santo Oficio (1914-1930). Para sus datos biográficos cf. Diccionario de historia eclesiástica de España, cit. (n. 6), Suplemento, p. 489; Diccionario biográfico español, cit. (n. 6), XXXIV, pp. 778-782; Enciclopedia cattolica (Città del Vaticano, 1949-1954), VIII, coll. 743-745; Catholicisme. Hier, aujourd'hui, demain, J ACQUEMET, G. (dir.), (Hamm, 1990-), VIII, coll. 1236-1238; BiographischBibliographisches Kirchenlexikon, BAUTZ, Friedrich Wilhelm (ed.), V, coll. 1331-1333; Diccionario critico de juristas españoles, portugueses y latinoamericanos, cit. (n. 25), III, pp. 368-370. Apuntes autobiográficos y sobre las figuras de los pontífices Pío X y Benedicto XV en MERry DEL VAL, Rafael, Impressioni e ricordi (Padova, 1925); Él mismo, Memorias del Papa Pio X (Madrid, 1946). El original de esta última obra fue redactado en inglés. Al morir el cardenal, su albacea guardó el manuscrito y en 1939 dio su permiso para la edición inglesa. Fue traducido al castellano en 1946, con prólogo de Antonio García y García, arzobispo de Valladolid.

${ }^{45}$ Cfr. Fantappiè, Carlo, cit. (n. 41), pp. 896-897.

${ }^{46}$ José Calasanz Vives y Tutó, OFM Cap. (Sant Andreu de Llavaneres [Barcelona], 15/02/1854 - Monte Porzio Catone [Roma], 07/09/1913), ingresó con quince años en la orden capuchina. Fue enviado a Guatemala, California y Toulouse, donde acabó los estudios filosóficos y realizó los de Teología. Allí mismo, tras una breve estancia en Ecuador, recibió la ordenación presbiteral en 1877. Director de la Escuela Seráfica en Perpignan. Tras la supresión de las órdenes religiosas por el gobierno francés en 1880 se instaló en Cataluña. Fue creado cardenal por León XIII en 1899. Consultor del tribunal del Santo Oficio (desde 1887) y de 
más influyentes del pontificado de Pío X, del que fue confesor y fiel confidente ${ }^{47}$. Su prestigio como canonista era ampliamente reconocido ${ }^{48}$. En relación con la reforma del derecho canónico, junto con Rampolla y otros cardenales, era favorable a la conservación del Corpus Iuris Canonici, con las necesarias enmiendas, y la adición de una nueva colección que reuniera todas las leyes vigentes. Para hacer más asequible el estudio y la práctica del derecho proponía, siguiendo el modelo justinianeo, la redacción de un "riassunto, breviario, etc., in forma di codice per articoli, capi, etc., citando le fonti del Corpus juris". En el congreso de cardenales del 26 al 28 de julio de 1904 se manifestó poco favorable a la subdivisión del schema en partes, secciones, títulos, capítulos, etc., siendo partidario de mantener los títulos y el orden de las Decretales ${ }^{49}$.

Ya durante los trabajos codificatorios fue uno de los principales canales de coordinación del pontífice con las comisiones codificatorias. Entre las fuentes del Código se encuentran, al menos, unos 26 documentos emanados por la Congregación para los Religiosos mientras que él fue prefecto ${ }^{50}$. Consta su participación en la revisión de los Schemata del Libro IV "De Processibus" 51.

Además de su labor i n te r n a, Vives y Tutó fue elegido por los obispos españoles -junto con Vicente Fernández Villa- como su representante en Roma, de modo que pudiera transmitir fidedignamente las proposiciones nacionales en las reuniones de los consultores. A estos efectos sería de gran interés el estudio de la correspondencia personal del cardenal con el episcopado español. En el

las congregaciones para los Ritos (desde 1889), Propaganda Fide (desde 1893), del Concilio (desde 1894) y para los Asuntos Eclesiásticos Extraordinarios (desde 1895); confesor de Pío X y prefecto de la Congregación para los Religiosos (1908-1913). Cfr. Serra DE MANRESA, Valentí, El Cardenal Vives i Tutó (1854-1913). Aspectes biogräfics i projecció eclesial, en Analecta Sacra Tarraconensia, 77 (2004), pp. 233-272; ÉL MISMO, El capuchino José de Calasanz de Llavaneres, cardenal Vives y Tutó (1854-1913). Su actuación durante los pontificados de León XIII y Pío X, en Archivum Historiae Pontificiae, 44 (2006), pp. 173-205; Diccionario de historia eclesiástica de España, cit. (n. 6), IV, pp. 2782-2783; Diccionario biográfico español, cit. (n. 6), L, pp. 358-362; Biographisch-Bibliographisches Kirchenlexikon, cit. (n. 44), XII, coll. 1535-1545; DE LANGASCO, Agatángel, El cardenal Vives y la codificación del derecho canónico, en Revista Española de Derecho Canónico, 10 (1955), pp. 457-475; de Barcelona, Antonio María, El cardenal vives y Tutó de la Orden de Frailes Menores Capuchinos (Barcelona, 1916). Una breve descripción de sus obras en ibíd. pp. 396-405; el elenco de sus libros y opúsculos en pp. 481-500.

${ }^{47}$ Tal fue su influencia y amistad que algunos medios vaticanos llegaron a decir que era el "monopolizador de los valores espirituales de la Iglesia", y que imponía al papa sus decisiones: cfr. DE Barcelona, Antonio María, cit. (n. 46), pp. 260-261.

${ }^{48}$ Federico Roldán, canónigo de Sevilla, poco después de la muerte de Vives y Tutó, lo presentaba como a uno de los canonistas más eminentes, afirmando que: "El Cardenal Vives y Tutó era tutto en las congregaciones romanas, era, como se suele decir, el alma. Tan universal era su justa y reconocida fama de canonista, llegando a afirmar el sapientísimo Wernz, hoy General de la Compañía de Jesús, que era el mejor canonista de nuestros días”: Correo Josefino, 17 (1913), p. 346, citado por Serra de Manresa, Valentí, El capuchino, cit. (n. 46), p. 198.

${ }^{49}$ Cfr. Fantappiè, Carlo, cit. (n. 41), pp. 675, 781-782.

${ }^{50}$ Cfr. ibíd., pp. 894-895. Sobre su actividad en esta congregación vid. DE MonTAGuT, J. Evangelista, El cardenal vives canonista y su labor al frente de la Congregación de Religiosos, en Estudios Franciscanos, $\mathrm{n}^{\circ}$ especial (1913), pp. 65-74.

${ }^{51}$ Cfr. DE Langasco, Agatángel, cit. (n. 46), p. 460. 
mismo sentido, una investigación pendiente todavía de realizar es el análisis detallado de los archivos de las congregaciones romanas con el fin de recopilar los borradores, minutas, memoriales y otros documentos que atestigüen su participación en la elaboración de del Código de Derecho Canónico ${ }^{52}$. Sin embargo, al igual que sucede con Merry del Val, la especial confianza y cercanía de Vives y Tutó con Pío X hace difícil que se pueda llegar a una reconstrucción completa de esta participación.

\section{En la Comisión de consultores ${ }^{53}$}

En la carta circular ${ }^{54}$ comunicada a los obispos del orbe católico por Merry del Val, se enumeraba en el cuerpo principal del texto a 17 consultores urbanos, entre los que estaba Vicente Fernández y Villa, agustino ${ }^{55}$. En nota a pie de página aparecían otros veinticinco consultores, entre ellos José Noval, dominico ${ }^{56}$. En los años siguientes se nombraron nuevos consultores y colaboradores, entre los

${ }^{52}$ Entre ellos las 15 cartas enviadas por Pío X a Vives y Tutó (del 26 de junio de 1904 al 7 de agosto de 1912) conservadas en el archivo de la Congregación de los Asuntos Eclesiásticos Extraordinarios (AES, Stati ecclesiastici, pos. 1288, fasc. 436, ff. 18r-42r [fotocopia]): cfr. Dieguez, Alejandro Mario, Carte Pio X. Scritti, omelie, conferenze e lettere di Giuseppe Santo. Cenni storici, inventario e appendice documentaria (Città del Vaticano, 2010), pp. xviii-xix. Aunque en relación directa con la codificación no se encuentra ninguna noticia ni en la obra anterior ni en las siguientes: ÉL MISMO, L'archivio particolare di Pio X. Cenni storici e inventario (Città del Vaticano, 2003); Dieguez, Alejandro Mario; Pagano, Sergio, Le carte del "Sacro tavolo". Aspetti del pontificato di Pio $X$ dai documenti del suo archivio privato (Città del Vaticano, 2006), 2 vols.

${ }^{53}$ José Noval da una lista del número de los consultores en su obra Codificationis Juris Canonici. Recensio bistorico-apologetica et Codicis Piano-Benedictini, notilia generalis doctrina ad studium novi Codicis Canonici propaedeutica (Romae, 1918), pp. 76-79. Un elenco más detallado en FANTAPPIÈ, Carlo, cit. (n. 41), pp. 1163-1168.

${ }^{54}$ Pergratum mibi (25/03/1904): en Acta Sanctae Sedis, 36 (1903-1904), pp. 603-604.

${ }^{55}$ (Olloniego [Oviedo], 29/11/1850 - Palma de Mallorca, 30/01/1917), realizó sus estudios eclesiásticos en el Seminario de Valladolid y un bienio en Roma. Profesor de Metafísica, Derecho natural y Teología natural en el Collegio Santa Monica, en Roma. Consultor de las congregaciones de Propaganda Fide, del Santo Oficio (1897) y para los Sacramentos (1908). Representante del episcopado español ante la comisión codificadora. Colaboró en los votos sobre el Título De Ordine y sobre el impedimento de afinidad. Cfr. Diccionario biográfico español, cit. (n. 6), XIX, pp. 611-612.

${ }^{56}$ (Lamuño [Asturias], 04/12/1861 - Madrid, 29/01/1938). Recibió su formación académica en Manila. Se trasladó a Roma en 1896 para dar clases de Derecho canónico en el Collegio Angelico. Consultor de las congregaciones de Propaganda Fide y de Seminarios y Universidades. En relación con la codificación, trabajó en la comisión especial de Iudiciis. Sus votos pueden consultarse en LLobell, Joaquín; De León, Enrique; NAvarrete, Jesús, Il libro "De processibus" nella codificazione del 1917. Studi e documenti. 1, Cenni storici sulla codificazione "de iudiciis in genere", il processo contenzioso ordinario e sommario, il processo di nullità del matrimonio (Milano, 1999), pp. 377407 y 569-608. Su participación en los verbales sobre el Libro De Iudiciis se puede consultar en ibíd., pp. 923 ss. Sobre su participación en la elaboración del Libro De Processibus cfr. RoBERTI, Franciscus, Codicis Iuris Canonici schemata De Processibus, en Acta Congressus Iuridici Internationalis (Romae, 1937), IV, pp. 29-42. Escribió una breve pero concisa recensión histórica sobre la codificación canónica: Noval, José, Codificationis, cit. (n. 53). Datos biográficos en Diccionario de historia eclesiástica de España, cit. (n. 6), III, p. 1782; Enciclopedia cattolica, cit. (n. 44), VIII, coll. 1967-1968. 
que estaban los españoles Eustasio Esteban, agustino ${ }^{57}$; Joaquín de san Simón Stock, carmelita descalzo ${ }^{58}$; Pedro Vidal, jesuita ${ }^{59}$ y Felipe Maroto, claretiano ${ }^{60}$.

${ }^{57}$ (La Horra [Burgos], 28/03/1860 - Lima, 26/04/1945). En 1883 es ordenado sacerdote en Roma, donde se doctoró en Derecho y obtuvo la licenciatura en ambos derechos en 1885, año en que regresa a España como profesor y bibliotecario del monasterio de El Escorial. En 1893 se trasladó al Perú, donde asistió a Gasparri cuando este fue nombrado delegado apostólico de este país. Prior general de la Orden de San Agustín (1926-1931). Funda y dirige la revista Analecta Augustiniana. Formado en la facultad jurídica del Seminario Romano de San Apolinar, fue nombrado consultor de la Congregación para los Religiosos (1906) y de la comisión pontificia para la codificación (28/04/1906). En esta tarea redactó observaciones a los cánones 1-1256 del Schema Codicis de 1916 [cfr. Fantappiè, Carlo, cit. (n. 41), pp. 727, 898, 1236]. Datos biográficos en: Álvarez FernándeZ, Jesús, Alphabetum Augustinianum, Institutum Historicum Augustinianum (http://iha.augustinians.net/index.php?page=biografie); Diccionario de historia eclesiástica de España, cit. (n. 6), II, p. 879; Cilleruelo, Lope, El Rvdmo. P. Maestro Fr. Eustasio Esteban, Prior General de la Orden de San Agustin (1860-1945) (Valladolid, 1955); Jorde, Elviro, Catálogo bio-bibliográfico de los religiosos agustinos de la Provincia del Santísimo Nombre de Jesús de las Islas Filipinas desde su fundación hasta nuestros días (Manila, 1901), pp. 769-770; LazCano, Rafael, Generales de la Orden de San Agustin. Biografía - Documentación - Retratos (= Studia Augustiniana Historia 10), Institutum Historicum Augustinianum (Roma, 1995), pp. 193-204.

${ }^{58}$ Manuel Olavarrieta (Dima [Vizcaya], 16/05/1854 - Bilbao, 30/05/1926). Como profesor se dedicó principalmente a las asignaturas de Teología dogmática, Teología moral y Derecho canónico. Consultor de las congregaciones de los Obispos y Regulares (1893), del Concilio (1897), de los Sacramentos (1908), de los Religiosos (1911), y de las comisiones para la Interpretación del Código (1917) y para los Nuevos Institutos Religiosos (1919). Durante muchos años confesor, colaborador y consejero de Gasparri. Desarrolló una gran labor de organización, síntesis y redacción del texto definitivo de los cánones con ocasión de las animadverisones llegadas a Roma tras la segunda consulta al episcopado. Cfr. DE s. LuIs GonZAGA, Amalio, El Rvdo. P. Joaquín de S. Simón Stock, en ElMonte Carmelo, 30 (1926), pp. 318-322; Él mismo, Analecta Ordinis Carmelitarum Excalceatorum, 1 (1926), pp. 222-224; LizARRAGA, José Javier, Centenario del reconocimiento de los Agustinos Recoletos como orden religiosa (1912-2012). El breve "Religiosas Familias" (16 septiembre 1912), en Recollectio, 36 (2013), p. 69.

${ }^{59}$ (Igualada [Barcelona], 20/07/1867 - Roma, 24/10/1938). Estudió Derecho canónico en la Universidad Gregoriana; tuvo como maestro a Wernz, a quien sustituyó en la cátedra. Consultor en las congregaciones para los Sacramentos (1908), del Concilio (1910), para los Religiosos (1918), para los Asuntos Eclesiásticos Extraordinarios (1920) y del Santo Oficio (1924), y de la Comisión para la Interpretación auténtica del Código (1917). Redactó votos para el título De Clericis y revisó el Schema Codicis de 1916. Cfr. O’Neill, Charles E.-Domínguez, Joaquín María (eds.), Diccionario histórico de la Compañia de Jesús. Biográfico-temático, (Roma-Madrid, 2001), IV, pp. 3946-3947; Enciclopedia cattolica, cit. (n. 44), XII, coll. 1389.

${ }^{60}$ Felipe Maroto Martín (Garcillán [Segovia], 26/05/1875 - Roma, 11/06/1937). Sus primeros estudios los realiza en el seminario claretiano de Segovia. Estudia Derecho canónico y civil en el Seminario Romano de san Apolinar, de donde fue profesor de Instituciones canónicas, Historia de las fuentes y Texto. Fue elegido superior general de la orden en 1934. Consultor de las congregaciones para los Religiosos (1912), del Santo Oficio (1913), de Propaganda Fide (1922) y de Estudios. Asesor personal del cardenal Bisleti, que fue miembro de la comisión encargada de la redacción final del Código; gozó de la especial confianza del cardenal Gasparri, que le consultó personalmente sobre el orden de los Libros IV y V; miembro de la reducidísima comisión que realizó la tercera y última revisión final del Código para la que escribió unas Adnotationes ad Librum quartum Codicis. Fue, junto con su discípulo Arcadio María Larraona, uno de los fundadores de la revista Commentarium pro Religiosis. Cfr. Goyeneche, Siervo, Balance de la codificación, en Estudios de Deusto, 17 (1961), p. 105; Diccionario biográfico español, cit. (n. 6), XXXII, pp. 639-641; http://www.claret.org/es/calendario-cmf/11-julio/p-felipe-maroto-superior-general. 


\section{Entre los colaboradores externos}

No existe ningún elenco oficial de este grupo, siendo la de Fantappiè la reconstrucción más lograda ${ }^{61}$. El único español que consta es Juan Bautista Ferreres, jesuita $^{62}$. No llegaron a participar ni Ramón Alsina Aloy ${ }^{63}$, catedrático de Teología moral, al que se le habían asignado las materias De locis et temporibus sacris y De culto divino, que se excusó por motivos de edad y salud; ni José Cadena y Eleta, probablemente con motivo de su reciente consagración episcopal ${ }^{64}$.

\section{Participación de los obispos}

La participación de los obispos españoles en la elaboración del Código, principalmente mediante sus postulata y animadversiones, es un ámbito totalmente pendiente de investigación. Para ello resulta obligada la consulta de las obras compiladas por Bernardino Klumper: Postulata Episcoporum in ordine digesta, Typis Vaticanis (Romae, 1905), 283 pp.; Appendix ad Postulata Episcoporum, Typis Vaticanis (Romae, 1908), 68 pp $^{65}$.

\section{LA CANONÍSTICA ESPAÑOLA TRAS LA CODIFICACIÓN}

\section{El Código canónico en las Cortes españolas ${ }^{66}$}

La entrada en vigor del Código de Derecho Canónico vino a alterar, en parte, el régimen del derecho eclesiástico español. Tal vez el ejemplo más significativo sea el del ámbito matrimonial. El Código canónico de 1917 recogió en sustancia las disposiciones tridentinas y el decreto Ne temere, que eran leyes del Reino ${ }^{67}$. Sin

${ }^{61}$ Cfr. Fantappiè, Carlo, cit. (n. 41), pp. 1217-1234.

${ }^{62}$ Juan Bautista Ferreres Boluda (Ollería [Valencia], 28/11/1861 - Valencia, 29/12/1936), realizó sus estudios eclesiásticos en el Seminario Conciliar de Valencia. Obtuvo la licenciatura de Filosofía y Letras por la Universidad de Zaragoza. Profesor de Moral y Derecho canónico en la facultad teológica de Cugat de Vallés (1900-1918, 1924-1931). Entre 1918 y 1924 residió en Roma, donde colaboró con Pedro Vidal en los trabajos codificatorios. Cfr. Diccionario de bistoria eclesiástica de España, cit. (n. 6), II, p. 929; Diccionario biográfico español, cit. (n. 6), XIX, pp. 836-837; Diccionario bistórico de la Compañía de Jesús, cit. (n. 59), II, pp. 1409-1410; Enciclopedia cattolica, cit. (n. 44), V, coll. 1199.

${ }^{63}$ También firmaba como Jaume Ramón [Raymundo] Anisla Aloy (Espunyola [Barcelona], 31/08/1830 - Solsona [Lleida], 19/01/1907). Estudió en el seminario diocesano de Solsona y un año de Derecho canónico en Vic. Ordenado presbítero en 1857. Catedrático de Teología y Moral en su seminario de origen, del que también fue vicerrector. Dio clases también de Ascética y Mística. Cfr. http://jalsina1.eresmas.com/ramon_a_aloy.htm; Diccionari d'bistoria eclesiastica de Catalunya (Barcelona, 1998-2001), I, pp. 63-64.

${ }^{64}$ Cfr. Fantappiè, Carlo, cit. (n. 41), pp. 737-738.

${ }^{65}$ Conservados en Archivio Segreto Vaticano, Fondo CIC, scattole 6 y 4 respectivamente. Debe tenerse en cuenta que, por motivos de eficacia, Klumper omitió algunos postulata: cfr. Llobell, Joaquín; De León, Enrique; NAvarrete, Jesús, cit. (n. 56), pp. 47-48.

${ }^{66}$ Véase sobre esta cuestión Villada, P., El Código de Derecho Canónico en las Cortes españolas, en Razón y Fe, 51 (1918), pp. 413-424.

${ }^{67}$ El Código Civil, en su art. 75, reconocía "[...] las disposiciones de la Iglesia Católica y del Santo Concilio de Trento, admitidas como Leyes del Reino”. Sobre esta cuestión vid. VÁzQUEZ García-Peñuela, José María, La publicación en España del decreto Ne temere' como ley del Reino, en CatTaneO, Arturo (curatore), L'eredità giuridica di san Pio X (Venezia, 2006), pp. 323-334. 
embargo, no dejó de haber algunos cambios codiciales sobre los esponsales, la celebración del matrimonio y la disolución del vínculo.

El núcleo de los problemas entre las autoridades civiles y eclesiásticas versó principalmente sobre la incidencia en el régimen jurídico español de la nueva codificación, si debía incorporarse el nuevo Código a la legislación del Reino y, en su caso, sobre el modo en que debía tramitarse el pase regio. Sobre estas cuestiones, así como de los trámites diplomáticos entre autoridades españolas y vaticanas y el régimen concordatario español ha tratado José Luis Llaquet de Entrambasaguas en diversas ocasiones ${ }^{68}$.

Antes de su discusión formal en las Cortes españolas, el Código canónico había sido objeto de dos intervenciones en las mimas Cortes: el 24 de mayo de 1917 en el Senado ${ }^{69}$ y en la sesión de 29 de mayo del mismo año en el Congreso ${ }^{70}$. En el Senado se planteó el problema que suscitaba la promulgación del nuevo Código para el derecho catalán ${ }^{71}$, que tenía al Derecho canónico como derecho supletorio $^{72}$. Ante la moción del Sr. Garriga, el ministro de Gracia y Justicia, Álvaro Figueroa y Torres Mendieta -más conocido por su título de conde de Romanones- respondió que "el Papa, soberano extranjero, no puede alterar el régimen jurídico de los súbditos españoles"’3. El ministro afirmó que el derecho canónico supletorio que regía en Cataluña era el antiguo, no el actual, "porque de ser esto así, se reconocería que una potestad que no tiene soberanía en España podría legislar en ella" ${ }^{\text {"74 }}$.

En la sesión del Congreso el diputado Seoane inquirió al ministro de Gracia y Justicia, sobre la fecha de publicación del Código canónico en España y el trámite que se seguiría para que se convirtiese en ley del Reino ${ }^{75}$. El conde de Romanones respondió que su tramitación se realizaría mediante el instrumento del pase regio ${ }^{76}$.

Finalmente, el rey Alfonso XIII concedió el pase regio al nuevo código por

${ }^{68}$ Llaquet de Entrambasaguas, José Luis, Incidencia del CIC de 1917 en el derecho estatal y concordatario español, en MARTín, María del Mar (ed.), Entidades eclesiásticas y derechos de los Estados. Actas del II Simposio Internacional de Derecho concordatario. Almería, 9-11 de noviembre de 2005 (Granada, 2006), pp. 535-541; La correspondencia entre la Nunciatura española y la Secretaría de Estado vaticana con ocasión del pase regio del CIC de 1917 en España, en CatTaneO, Arturo, cit. (n. 67), pp. 217-221; La Discusión doctrinal acerca del código canónico de 1917 como ley del reino de España, en Revista de Dret Històric Català, 14 (2015), pp. 323-336.

${ }^{69}$ Cfr. Diario de las Sesiones de Cortes: Senado, n. 45, 24/05/1918, 534.

${ }^{70}$ Diario de las Sesiones de Cortes: Congreso de los Diputados, n. 46, 29/05/1918, 1263.

${ }^{71}$ Sobre esta cuestión vid. en primer lugar ToRTOSA, Diego, en Revista General de Legislación y Jurisprudencia, 138 (1921), pp. 309-324, artículo que es reproducido en gran medida por LLAQUET De Entrambasaguas, José Luis, Controversias en torno al derecho supletorio catalán con ocasión de la promulgación del Código canónico de 1917, en Revista de Dret Històric Català, 2 (2002), pp. 171-201.

${ }^{72}$ Por Decreto de nueva planta de Felipe V del año 1716.

${ }^{73}$ El Debate, martes 4 de junio de 1918, p. 3.

${ }^{74}$ Ibíd.

${ }^{75}$ Sobre las dos intervenciones vid. Villada, P., cit. (n. 66), pp. 413-424.

${ }^{76}$ Debe tenerse en cuenta que el Código penal por entonces en vigor, el de 1870, sancionaba la publicación de bulas, breves o despachos de la corte pontificia sin el pase regio, pese a que la Constitución de 1876 volvió a declarar el catolicismo como religión de Estado, después de la Constitución librecultista de 1869. 
Real Decreto de 19 de mayo de $1919^{77}$, exactamente un año después de su universal entrada en vigor. Dicha aprobación fue precedida por un dictamen del Consejo de Estado, unánimemente favorable, y por su discusión en las Cortes españolas. No obstante el pase regio, el código no fue declarado como ley del Reino.

Algunos tribunales civiles consideraron que el Código de Derecho Canónico era ley civil directamente aplicable; sin embargo, el Tribunal Supremo sostuvo la posición contraria ${ }^{78}$ y los jueces, cuando las normas codiciales entraban en conflicto con el derecho concordatario, aplicaban este por tener condición de tratado internacional ${ }^{79}$.

\section{Reacciones ante la promulgación del Código canónico}

Tras la promulgación del Código canónico por Benedicto XV las reacciones entusiastas por parte de la canonística española fueron prácticamente unáni$\mathrm{mes}^{80}$, como así lo manifiesta Valentí: "Con respecto a la publicación del nuevo Código, juzgo firmemente que ha sido acogida con grandes muestras de estima y reconocimiento por el Clero español y por los doctos canonistas de nuestros Seminarios y Universidades" $"$.

"Fecha para siempre memorable" que hemos podido alcanzar la realización de la obra desde tanto tiempo deseada" 84 , proclamaba Noval; "[los] vivísimos anhelos del orbe católico, que suspiraba hacía

${ }^{77}$ Gaceta, 20 de mayo de 1919.

78 "El Gobierno se limitó a concederle el pase [al CIC] por Real decreto de 19 de mayo de 1919, sin promulgarlo ni declararlo ley de la Nación, como declaró el Concordato de 1851 y los Convenios de 1859 y 1904": STS de 30 de abril de 1935, en Revista General de Legislación y Jurisprudencia. III. Jurisprudencia Civil, t. 218, p. 712.

${ }^{79}$ Cfr. Llaquet de Entrambasaguas, José Luis, Incidencia, cit. (n. 68), pp. 540-541.

${ }^{80} \mathrm{Al}$ igual que sucedió con la ciencia canónica internacional: $c f r$. GómEZ-IGLESIAS, Valentín, La ricezione del codice del 1917 nella dottrina e nell'insegnamento, en BAURA, Eduardo; ÁlvarEZ DE LAs Asturias, Nicolás; Sol, Thierry (a cura di), cit. (n. 1), pp. 72-119 (específicamente p. 80).

${ }^{81}$ Valentí, J. I., El nuevo Código canónico y una obra importante de derecho, en Revista Eclesiástica, 42 (1918), p. 555.

${ }^{82}$ Mostaza, Miguel, en Sal Terrae, 6 (1917), p. 540, también en Regatillo, Eduardo F., Cuestiones, cit. (n. 3), pp. 24-35.

${ }^{83}$ Miguel Mostaza Rodríguez de Medio, SJ (Santa Colomba de Sanabria [Zamora], 01/07/1867 - San Sebastián, 17/09/1943), estudió en el seminario de Astorga y se licenció en teología en Salamanca. En 1890 recibe la ordenación sacerdotal y tres años más tarde ingresa en el noviciado de la Compañía de Jesús. Estudia en la Universidad Gregoriana, de la que llegará a ser decano tras un tiempo como catedrático en la Universidad Pontifica de Comillas. Encargado habitual de los comentarios canónicos en la sección "Documental" (Documentos textuales, anotados, comentados, concordados y explicados) de la revista Sal Terrae: Con anterioridad había ido publicando por artículos sus comentarios al Código: El nuevo Código de Derecho Canónico promulgado por Benedicto XV, en Sal Terrae, 6 (1917), pp. 540-547, 617-627; Derechos y deberes de los párrocos según el nuevo Código, ibíd., 7 (1918), pp. 143-146; Derechos y deberes de los eclesiásticos según el nuevo Código, ibíd., pp. 222-227; Nueva disciplina matrimonial en el actual Código canónico, en Ibid., pp. 365-372; Privilegios más usuales de los Ordinarios y de los curas en el nuevo Código, ibíd., pp. 526-532; Censuras 'latae sententiae' según el nuevo Código, ibíd., pp. 601-608, 769-782, 919-932. Cfr. https:// es.wikipedia.org/wiki/Miguel_Mostaza_Rodr\%C3\%ADguez_de_Medio

${ }^{84}$ Noval, José, El Código, cit. (n. 40), p. 142. 
tiempo por una nueva codificación del derecho eclesiástico mejor acomodada de la época presente, se han visto felizmente satisfechos con la publicación del nuevo Código" $" 85$, secundaba Arquer ${ }^{86}$.

De un modo bastante grandilocuente se manifestaban otros autores, como Juan Aguilar Jiméne $z^{87}$ : acontecimiento que "abrirá de seguro una verdadera época de gloria y grandeza para la Iglesia Católica [...] este hecho, que considero el más culminante de la Historia eclesiástica de nuestro tiempo y de trascendencia suma, no solo en el orden religioso, sino en todo el orden social humano"88. Valentí, siguiendo a Aguilar Jiménez, afirmaba: "considero este acontecimiento como el más culminante de la Historia eclesiástica de nuestro tiempo y de trascendencia suma, no solo en el orden religioso, sino en todo el orden social humano" ${ }^{89}$. Torrubiano, por su parte, manifestaba que "la nueva codificación del Derecho canónico ha sido uno de los mayores aciertos del Pontificado Romano" "90; Tortosa que "no se trata solo de la promulgación de un Código, siempre importante, sino de la promulgación de un Código de trascendencia singularísima, por su universalidad, por su fin, por las circunstancias mismas en que aparece" "91; y Ferreres: "acaba de recibir la Iglesia, con el Código canónico, el más insigne monumento de codificación canónica que han visto los siglos" "

Las ventajas que aportaban las características técnicas de la codificación eran evidentes para todos. Eduardo Fernández Regatillo, recogiendo expresiones acuñadas para manifestar la insostenible situación anterior, se hacía eco del alivio experimentado por la canonística: "aquel ingens onus camellorum [...] aquella rudis indigestaque moles [...] se convirtió en un manojo breve, claro y ordenado de 2414 cánones, que cualquier estudiante puede llevar en el bolsillo" "93. Y Maroto: "lo que sobre todo es de apreciar en el nuevo Código es la forma en que los cánones están redactados; pues [...] en el nuevo Código se nos dan las leyes eclesiásticas reducidas a la forma más breve y estricta de artículos; de donde [...] derívanse muchas ventajas de utilidad, eficacia y comodidad, tanto para el uso y la práctica forense como para el estudio y conocimiento de los cánones"94.

Muñoz destacaba también la mayor facilidad para el estudio, que podría reali-

${ }^{85}$ DE Arquer, Miguel, El nuevo Código de derecho canónico, en Reseña Eclesiástica, (1917), p. 477.

${ }^{86}$ Miguel de Arquer (Arenys de Mar [Barcelona], 1876 - Barcelona 1969], estudió en el seminario de Barcelona y en la Universidad Pontifica de Tarragona. Recibió la ordenación sacerdotal en 1902. Catedrático de Teología moral en el seminario de Barcelona y examinador sinodal. Cfr. Diccionari d'historia eclesiastica de Catalunya, cit. (n. 63), I, pp. 127-128. Publicó una serie de artículos sobre el nuevo Código en la revista Reseña Eclesiástica a lo largo de los años 1917 y 1918.

${ }^{87}$ Canónigo magistral de la catedral de Jaén (06/12/1898), de donde se trasladó a Madrid como canónigo doctoral.

${ }^{88}$ Aguilar Jiménez, Juan, cit. (n. 10), p. 258.

${ }^{89}$ VALENTí, J. I., cit. (n. 81), p. 553.

${ }^{90}$ Torrubiano, Jaime, Novísimas instituciones, cit. (n. 9), I, p. 5.

${ }^{91}$ TortosA, Diego, en Revista General de Legislación y Jurisprudencia, 131 (1917), p. 399.

${ }^{92}$ Ferreres, Juan Bautista, El Código canónico. Monumento insigne de Pio X y Benedicto XV, en Razón y Fe, 48 (1917), p. 502.

${ }^{93}$ Regatillo, Eduardo F., La Enseñanza, cit. (n. 3), pp. 9-10.

${ }^{94}$ Maroto, Felipe, cit. (n. 5), I, pp. 169. 
zarse en su mayor parte al margen de las leyes civiles ${ }^{95}$. Son generalizadas también las referencias a la ventaja de encontrar todas y solas las leyes eclesiásticas en una sola fuente y la mayor facilidad para su conocimiento y aplicación en los tribunales.

Pero más interesantes todavía son los comentarios a las características técnicas de la codificación, especialmente la de su forma. Ferreres sintetizaba: "el nuevo Código canónico procede por medio de artículos breves, claros y sencillos, imitando los nuevos códigos civiles de Europa y América, lo cual es una grandísima ventaja por su brevedad y por su claridad" "96. Y Aguilar Jiménez llamaba la atención sobre la unidad armónica de su contenido al haberse elaborado de forma simultánea y en un solo lapso de tiempo ${ }^{97}$.

Maroto, por su parte: "el nuevo Código de las leyes eclesiásticas está ordenado según un sistema claro y racional, cuyas partes lógicamente se deducen y se encadenan entre sí. Por tal causa esta nueva colección aventaja en mucho en cuanto a esto, a todas las otras que hasta ahora habían estado en uso en la Iglesia" ". El mismo autor avanza que, en su disposición, el Código se aleja del sistema de las Decretales para adoptar el usado generalmente en los tratados de instituciones canónicas.

Giménez y Fernández ${ }^{99}$ recoge el sentir generalizado sobre el nuevo Código, que recibió un juicio crítico muy favorable: "se elogian principalmente: la claridad y sencillez en su lenguaje, salvo algunas faltas literarias que señala Falco; su precisión jurídica y técnica, excepto algunas anfibologías y uso de términos de curia que remarca Stutz, y su perfecta sistematización, a la que solo cabe oponer, con

${ }^{95}$ Mauro Muñoz, beneficiado de la diócesis de Burgos: cf. El nuevo Código de Derecho Canónico, en Revista Eclesiástica, 41 (1917), p. 444.

${ }^{96}$ Ferreres, Juan Bautista, El Código, cit. (n. 92), pp. 502-503. Algunas de estas expresiones están también reproducidas en sus Instituciones, t. 1, p. 37. Ahora bien, esta técnica no era una novedad absoluta en la Iglesia, pues, como pusieron de relieve numerosos autores, ya se había acudido desde mediados del siglo XIX a codificaciones parciales, como las constituciones Apostolicae Sedis moderationi (Pío IX, 12/10/1869, que codificó lo referente a las censuras latae sententiae), Officiorum ac munerum (León XIII, 25/01/1897, en relación a la censura y lectura de libros prohibidos), Conditae a Christo (León XIII, 08/12/1900), Sapienti consilio (Pío X, 02/08/1907, que regula la organización de la curia romana), etc. Sobre este asunto vid. Maroto, Felipe, cit. (n. 5), I, pp. 158-159; Campos y Pulido, José María, cit. (n. 40), pp. 377-378; Ferreres, Juan Bautista, La codificación, cit. (n. 29), pp. 368-369.

${ }^{97}$ Cfr. Aguilar JiméNeZ, Juan, cit. (n. 10), p. 447.

${ }^{98}$ Maroto, Felipe, cit. (n. 5), I, p. 168.

${ }^{99}$ Manuel Giménez y Fernández (Sevilla, 06/05/1896 - 27/02/1968), licenciado en Letras y en Derecho por la Universidad de Sevilla, doctor en Derecho por la Universidad Central. Se encargó de la enseñanza de numerosas materias: Derecho canónico, Derecho internacional público y privado, Derecho procesal, Derecho Político, Historia del derecho, Derecho natural, Derecho mercantil, Economía política y Hacienda Pública, Historia universal, Historia de la Iglesia, Historia del pontificado. Catedrático de Derecho canónico, Derecho internacional público y privado y de Historia de la Iglesia y de las Instituciones canónicas hispano-americanas. Desarrolló también carrera política como diputado a Cortes por Badajoz, vicepresidente de las Cortes y un breve periodo como ministro de Agricultura en el gobierno de Lerroux. Cfr. Diccionario de catedráticos españoles de derecho, cit. (n. 25); Diccionario biográfico español, cit. (n. 6), XXIII, pp. 62-63; Diccionario crítico de juristas españoles, portugueses y latinoamericanos, cit. (n. 25), I, pp. 375-378. 
Wernz, algunos lunares al tratar de los oficios y de las causas de beatificación" Campos y Pulido, por su parte, alaba la perfección del sistema científico del Código, a imitación del de los Estados modernos, que contiene, según su expresión "todo el derecho de aplicación a la Iglesia"".

Es interesante también observar la coincidente postura de los autores al comparar los sistemas compilatorio y codificatorio. Aguilar Jiménez sintetiza de modo magistral las inclinaciones de la doctrina por este último sistema, llegándolo a denominar el summum de la perfección legislativa ${ }^{102}$. También Postíus hace referencia a esta distinción, si bien posicionándose en un término medio entre las escuelas histórica y filosófica ${ }^{103}$.

Ahora bien, la canonística no dejaba de advertir los peligros e inconvenientes que podían suponer esa gran innovación y transformación jurídica. El mismo Aguilar Jiménez señalaba concretamente el trastorno del cauce social y la tendencia a demoler lo pasado ${ }^{104}$. López Ortiz ${ }^{105}$, en el prólogo a la primera traduc-

${ }^{100}$ Giménez y Fernández, Manuel, Instituciones jurídicas en la Iglesia católica (Madrid, 1940), I, pp. 115-117.

${ }^{101}$ Cfr. Campos y Pulido, José María, Legislación y jurisprudencia canónica novísima y Disciplina particular de España. Exposición y comentario de las más recientes disposiciones dictadas en el Pontificado de Su Santidad Pio Papa X [...] (Madrid, 1921), IV, pp. 5 y 15.

102 "A las razones generales anteriormente apuntadas debe añadirse una especialísima de metodización y forma científica, propia de la perfección jurídica y del carácter social legislativo de nuestro tiempo [...] se ha llegado hoy al sistema codificador, el summum, al menos en la forma, de la perfección legislativa. El compilador, con las amplias atribuciones que le eran conferidas desde los tiempos de desenvolvimiento jurídico del siglo XII en adelante, puede decirse que era un verdadero organizador del Derecho; pero el codificador contemporáneo es mucho más, un genuino creador social del Derecho mismo, pues tomando toda la materia jurídica de su época, todo el cúmulo de leyes de su pueblo y de su tiempo, las funde y depura en el crisol del análisis mental, reduciéndolas por el articulado a fórmulas breves y concisas que se conexionen y encadenen con perfecto engranaje y organización científica. Este sistema constructor del Derecho, desarrollado principalmente en la segunda mitad del siglo XIX, es una necesidad de la sociedad contemporánea [...] La Iglesia Católica [...] no podía por menos, al llegar el tiempo debido, de formar con su vasta y admirable legislación, monumento inmortal en la historia del espíritu, un grandioso Código": Aguilar Jiménez, Juan, cit. (n. 10), pp. 259, 261-265.

103 "Las compilaciones representan el oficio casi mecánico del que coordina las leyes y costumbres escritas. Las codificaciones muestran el papel de los jurisconsultos y filósofos del derecho que crean las leyes orgánicas de los pueblos. Aunque distintas ambas formas no deben separarse, porque las comisiones codificadoras no deben guiarse solo por la filosofía, sino también por las costumbres, a que tanta fuerza dan la razón, el tiempo y el sentimiento nacional. Colocados en medio de las escuelas histórica y filosófica creemos que los códigos han de inspirarse siempre en la historia y la filosofía de los pueblos a cuyo gobierno se encaminan": Postíus y SALA, Juan, El Código canónico aplicado, cit. (n. 7), p. 124.

${ }^{104}$ Aguilar JiméneZ, Juan, cit. (n. 10), p. 265.

${ }^{105}$ José Ángel López Ortiz (San Lorenzo del Escorial [Madrid], 10/07/1898 - Madrid, 04/03/1992), ingresó en los agustinos en 1917 y recibió la ordenación sacerdotal en 1922. Realizó sus estudios eclesiásticos en el Seminario Conciliar de Madrid y en el Real Monasterio de El Escorial. Estudió Derecho en la Universidad Central y en la Universidad de Zaragoza. Catedrático de Historia del Derecho por la Universidad de Santiago y de Historia de la Iglesia y del Derecho Canónico por la Universidad Central. Académico de las reales academias de Ciencias Morales y Políticas y de Jurisprudencia y Legislación. Obispo de Tuy-Vigo y vicario general castrense. Cfr. Diccionario de catedráticos españoles de derecho, cit. (n. 25); Diccionario biográfico 
ción íntegra al castellano realizada por la BAC, señalaba también las tendencias revolucionarias y de cambios constitucionales que marcaron las codificaciones civiles para, a continuación, constatar que tales cambios fundamentales no se habían producido en la Iglesia ${ }^{106}$. Ante la confrontación entre exigencias formales y dificultades para adaptar su contenido, la Iglesia sacrificó la forma ${ }^{107}$, aspecto este también confirmado por Villaplana ${ }^{108}$.

No querría finalizar este apartado sin hacer referencia a las precisiones hechas por dos autores de nota sobre el carácter exclusivo del Código. Felipe Maroto, comentando el c. 6 sobre la abrogación del derecho anterior termina afirmando que "por consiguiente, el Código no excluye en absoluto todas las otras leyes eclesiásticas"109. José Noval confirma esta postura haciendo frente a la máxima "quod non est in Codice non est in mundo": "erraría, pues, quien creyese que para saber cuáles son todas y cada una de las leyes de la Iglesia vigentes de hoy en adelante y poder decidir en cualquiera materia canónica le basta aprender de memoria el Código o leerlo en cada caso que ocurra". Y saca de ello una consecuencia de gran calado: "En una palabra: para entender, no digamos todas las leyes eclesiásticas, pero sí las principales y el Código como tal, es indispensable ser canonista; y para ser canonista se necesita, hoy como antes, saber y entender el Derecho vigente hasta la promulgación del Código, ya explícita, ya implícitamente, y saber compararlo con el Derecho antiguo escrito, con el consuetudinario, con los principios generales del Derecho, etc." "110. Y, a continuación, da razón de los motivos por los que el legislador no optó por una abrogación absoluta ${ }^{111}$.

español, cit. (n. 6), XXX, pp. 657-659; Diccionario crítico de juristas españoles, portugueses y latinoamericanos, cit. (n. 25), I, pp. 493-494.

106 "Las primeras tentativas de codificación se inspiraron en la idea ambiciosa de establecer de nuevo las instituciones fundamentales sobre bases teóricas, apriorísticas, condensación con frecuencia de ideas revolucionarias, en contra de un pasado, juzgado, desde luego, como injusto. La Iglesia no ha pasado por este movedizo período constituyente, ni podía pasar por él. Su código no ha sido un ensayo reformista [...] Otra diferencia fundamental que le separa de los códigos vigentes en los diferentes Estados: [...] el Codex iuris canonici contiene tan poca materia de lo que solemos catalogar como Derecho privado, que casi podemos considerarlo como exclusivamente consagrado a la constitución y régimen de la Iglesia”: LópEz OrTiz, José, en Código de Derecho Canónico (Madrid, 1945), p. xviii.

${ }^{107}$ Ibíd. p. xxxi.

108 "El nuevo Código confirma en el fondo el derecho tradicional de la Iglesia con pequeñas variantes que han exigido los tiempos y la moderna ciencia jurídica [...] El nuevo Derecho canónico no ha sido vaciado en el molde de ningún Código civil moderno ni antiguo: es el verdadero reflejo del espíritu de la Iglesia y del don de su perpetuidad”: Villaplana, J., Novísimo derecho canónico, en Revista Eclesiástica, 41 (1917), p. 50.

${ }^{109}$ Maroto, Felipe, cit. (n. 5), I, p. 171.

${ }^{110}$ Noval, José, El Código, cit. (n. 40), p. 169.

111 "Parece, a primera vista, que habría sido muy cómodo y muy útil para el estudio y el conocimiento del Derecho Canónico reunirlo todo en una sola fuente, de modo que no se hubiese de recurrir a otra, no hay para suplirlo, mas ni aún para interpretarlo. Pero no era tarea fácil, ni breve, ni prácticamente posible la realización de semejante obra, dado el principio establecido por el legislador para que sirviese de fundamento y punto de partida a la codificación, a saber: conservar y respetar generalmente el Derecho antiguo, si bien introduciendo las derogaciones y modificaciones necesarias": ibíd., p. 170. 


\section{Manuales y otras publicaciones ${ }^{112}$}

Aunque el decreto de la Sagrada Congregación de Seminarios de 7 de agosto de 1917 declaraba que los alumnos no necesitaban ningún otro libro fuera del propio Código, lo cierto es que hubo una gran profusión de literatura canónica, como no podía ser de otra manera.

La intención de este apartado es dar noticia de la primera y principal bibliografía publicada por autores españoles tras la promulgación del Código, que por decisión metodológica no irá más allá del año 1940. No se hará, por tanto, referencia tampoco a las obras de autores extranjeros que también fueron de uso común en España para la enseñanza del derecho canónico ${ }^{113}$, ni a las numerosas obras realizadas por autores españoles sobre materias particulares, como tratados de derecho matrimonial, penal, derecho parroquial ${ }^{114}$, etc.

Dada la dificultad para clasificar de modo riguroso cada una de las obras según su utilización para las clases de Instituciones ${ }^{115}$ o de Texto, he optado por señalar de seguido las obras pertenecientes a un mismo autor. De las más importantes de ellas se dará una información básica.

Sin duda alguna, el autor más prolífico es Juan Bautista Ferreres, tanto en manuales y monografías como en artículos en diferentes revistas. El mismo año de la promulgación del Código dio a la imprenta sus Instituciones canónicas con arreglo al novísimo código de Pio X [...] y a las prescripciones de la disciplina española y de la América latina, 2 vols. (Madrid, 1917) ${ }^{116}$.

El primer volumen incluye un libro preliminar, con una introducción histórica y doctrinal, y el estudio de los dos primeros libros del Código, es decir, la materia más propia de las Instituciones. El segundo volumen trata los tres restantes libros, omitiéndose la mayor parte de los sacramentos para adaptarse a la extensión propia de las Instituciones.

Como complemento a la materia que deja de tratar remite principalmente al segundo volumen de su compendio de teología moral ${ }^{117}$ y a otras monografías suyas que precedieron y prepararon sus Instituciones. Una de ellas es: Los esponsales

\footnotetext{
${ }^{112}$ Sobre la producción libraria en España durante los decenios posteriores a la promulgación del Código deben tenerse en cuenta las especiales dificultades y trastornos que produjeron la Guerra Civil española (1936-1939) y la Segunda Guerra Mundial (1939-1945).

${ }^{113}$ Véase, por ejemplo, las obras recomendadas en Regatillo, Eduardo F., La Enseñanza, cit. (n. 3), pp. 13 y 17.

${ }^{114}$ En este ámbito fueron de obligada referencia las obras Derecho parroquial según el "Codex Iuris Canonici” de Tomás Muniz Pablos (1ª ed., Madrid-Sevilla, 1918) y Eduardo F. Regatillo (1 ${ }^{\text {a }}$ ed., Santander, 1951).

${ }^{115}$ Aunque el decreto de 7 de agosto de 1917 de la Congregación de Seminarios y Universidades establecía que en las clases de Texto debía seguirse como único plan el establecido por el Código, algunos autores entendieron que esa disposición no afectaba a los libros de Instituciones. Cfr. Fuster, Fernando, en Razón y Fe, 55 (1919), p. 249.

${ }^{116} \mathrm{He}$ tenido acceso a la segunda edición, de 1918.

${ }^{117}$ Compendium theologiae moralis ad norman novissimi codicis canonici, 2 vols. (Barcinone, 19181919). La primera edición en lengua española apareció en 1920: Compendio de teología moral según la norma del novísimo código canónico. Otras obras suyas en el ámbito moral: Epitome compendii theologiae moralis ( $2^{\mathrm{a}}$ ed., Barcinone, 1918); y su versión castellana Epitome del compendio de teología moral (Barcelona, 1921).
} 
y el matrimonio según la novísima disciplina. Comentario canónico-moral sobre el decreto $\mathrm{Ne}$ Temere' ( $5^{a}$ ed., Madrid, 1911). En el prólogo a la $2^{a}$ edición castellana de las Instituciones hace referencia a otra obra para el estudio más detenido del matrimonio y del orden ${ }^{118}$ : Derecho sacramental y penal especial. Con arreglo al novísimo Código de Pío $X$, promulgado por Benedicto XV, a las declaraciones subsiguientes de la Santa Sede y a las prescripciones de la disciplina española y de la América Latina (Barcelona, 1918) ${ }^{119}$. En el libro IV, de los procesos, colaboró Pedro Vidal. En la tercera edición (Barcelona, 1923), el título viene ligeramente modificado: Derecho sacramental (particularmente del matrimonio) y penal especial [...]

Sobre materia canónica adaptó su obra Las religiosas según la disciplina vigente [...] comentarios canónico-morales ( $3^{\mathrm{a}}$ ed., Madrid, 1908) al Código canónico: Las religiosas según la disciplina del nuevo Código de Derecho Canónico. Comentarios canónicomorales (Madrid, 1920).

También muy relacionado con el ámbito canónico se sitúa su colaboración en la obra de Jean Pierre Gury, Casus conscientiae. Propositi ac soluti A.P. Joanne Pedro Gury, S.I [...] (Barcinone, 1903). Tras la promulgación del Código se volvió a publicar bajo el siguiente nombre: Casus conscientiae. Novis casibus aucti, novissi codici canonico, dispositionibus iuris hispani ac lusitani, decretis concilii plenarii Americae Latinae necnon conc. prov. Manilani earumdemque regionum legibus peculiaribus, 2 vols. (Barcinone, 1920-1921).

En su momento, se dio información precisa del breve pero sustancioso folleto de José Noval, Codificationis Juris Canonici. Recensio bistorica-apologetica, por lo que no se le dedica aquí más espacio. Sí haré referencia a su importante obra Commentarium Codicis Iuris Canonici. Liber IV, De processibus, publicada en tres tomos: De iudiciis, De causis beatificationis servorum Dei et canonizationis beatorum, De modo procedendi in nonnullis expediendis negotiis vel sanctionibus poenalibus applicandis (Augustae Taurinorum - Romae, 1920) $)^{120}$.

En 1918 Juan Postíus y Sala publicó El Código canónico aplicado a España en forma de Instituciones $^{121}$. Define su obra como especie de Instituciones canónicas, con el propósito de "historiar, sintetizar y analizar todos los institutos del novísimo Código Canónico, siguiendo el método legal” y poniendo en relación los preceptos codiciales con la legislación concordada para España ${ }^{122}$.

${ }^{118} \mathrm{La}$ tarea viene solicitada por profesores universitarios y abogados que sugieren, como complemento a las Instituciones, un tratamiento más detallado del derecho sacramental, especialmente de los sacramentos del matrimonio y del orden y del derecho penal especial.

${ }^{119}$ Regatillo recomienda esta obra para el estudio del Libro III del Código: $c f r$. Regatillo, Eduardo F., La Enseñanza, cit. (n. 3), p. 17.

${ }^{120}$ Regatillo recomienda esta obra para el estudio del Libro IV del Código: $c f r$. ReGATILLO, Eduardo F., La Enseñanza, cit. (n. 3), p. 17.

${ }^{121}$ Parte de su libro fue anticipada en forma de artículos: cfr. Codex Juris Canonici, en Ilustración del Clero, 11 (1917), pp. 217-225, 233-240, 249-258, 265-273, 281-284, 297-301, 313-317, 329333; El código canónico aplicado a España, en Ilustración del Clero, 12 (1918), pp. 255-256, 278-280, 297-298. La obra apareció en 1918 bajo otro título y tras varias ediciones y revisiones quedó como definitiva la cuarta edición, de 1926, revisada por Felipe Clemente de Diego, catedrático de la Universidad Central, y en la que se añade la legislación positiva, común y foral de España.

${ }^{122}$ Cfr. p. ix. 
El plan de la obra sigue fielmente los cinco Libros del Código, pero son precedidos por un libro Isagógico, o introducción general a los estudios jurídicos, según los programas vigentes en las universidades y seminarios españoles de aquel tiempo ${ }^{123}$. Esta introducción incluye contenidos de técnica jurídica, geografía y cronología jurídica, historia y fuentes de la legislación. Postíus realizó también un breve resumen en 173 páginas de la obra anterior, con el título El Código canónico o descripción y resumen del Codex Iuris Canonici (Madrid, 1918) ${ }^{124}$.

Un influjo todavía mayor que la obra de Postíus tuvo la de su hermano de religión, Felipe Maroto, Institutiones iuris canonici ad normam novi codicis, en dos volúmenes, el segundo de ellos en colaboración con Juan Postíus ${ }^{125}$. La obra fue traducida al castellano en el mismo año 1919 en dos volúmenes bajo el título Instituciones de derecho canónico de conformidad con el nuevo Código. Seguida de las Lecciones de disciplina eclesiástica de España.

La obra se destina principalmente a los seminarios y universidades, en los que por lo general se daban lecciones de Instituciones y no de Texto ${ }^{126}$. Al igual que las publicaciones examinadas anteriormente incluye un libro o parte introductoria. Pero dejemos que lo explique el autor con sus propias palabras: "el orden de la exposición se acomoda, por lo general, a la división en cinco libros y a la distribución de materias establecida en el nuevo Código; sin embargo, al libro primero o de las Normas generales, ha sido preciso añadir muchas cosas, por ser pocas las que allí se contienen, pues son postulados jurídicos que se dan por conocidos [...] Ello integra lo que por otro nombre se denomina Prolegómenos del Derecho o Introducción al Derecho, o Propedéutica del Derecho, y comprende noticias generales y ciertas noticias históricas que es necesario, o por lo menos muy útil, conocer de antemano" 127 .

También pronta fue la publicación de los Comentarios al Código Canónico, 3 vols. (Madrid, 1919-1922), de Federico Santamaría ${ }^{128}$. Tras una breve introducción

${ }^{123}$ Por entonces, la mayor parte de las cátedras de derecho canónico en la universidad española estaban ocupadas por clérigos que aplicaban un estricto método exegético. Sobre esta cuestión y la aplicación del método exegético y el método sistemático en la doctrina científica posterior a la codificación cfr., entre otros, Ciáurriz, María José, El pensamiento científico de Pedro Lombardia (a través de su análisis por Javier Hervada), en Ius Canonicum, 118 (2019), pp. 669-671 y 676-684; Gómez-IgLESiAs, Valentín, De la centralidad de la ley al primado de la persona en el derecho de la Iglesia. Historia y perspectivas canónicas en el centenario del Código de 1917, en Ius Canonicum, 114 (2017), pp. 506-509.

${ }^{124}$ He consultado la tercera edición, de 1918 . No he encontrado referencia ninguna de la primera, que debe ser también del mismo año. La cuarta edición, también de 1918, es corregida y notablemente aumentada con 424 páginas.

${ }^{125}$ Fue publicada en 1919. El segundo volumen lleva por subtítulo: Accedunt pro Hispanis Lecciones de disciplina eclesiástica de España, complemento realizado por Juan Postíus.

${ }^{126}$ A pesar de esto, Regatillo recomienda para las clases de Texto sobre el Libro I del Código la obra de Maroto: $c f r$. Regatillo, Eduardo F., La Enseñanza, cit. (n. 3), p. 17.

${ }^{127}$ Maroto, Felipe, cit. (n. 5), I, pp. 8-9.

${ }^{128}$ Federico Santamaría Peña, doctor en derecho canónico y párroco de la Iglesia del Carmen y San Luis (Madrid), autor prolífico, publicó en la misma imprenta también en ámbito canónico: Esponsales, matrimonio, divorcios y pleitos matrimoniales, con arreglo al nuevo Código Canónico y a la legislación civil, para utilidad de abogados y sacerdotes; Variaciones del nuevo Código Canónico en la teología 
propedéutica, procede a la transcripción latina de cada uno de los cánones y su traducción al español junto con los respectivos comentarios de extensión variable.

En 1919 publicó Jaime Torrubiano Ripoll sus Novísimas instituciones de derecho canónico. Acomodadas al nuevo 'Código' ordenado por S. S. el Papa Pí X y promulgado por la Santidad de Benedicto XV, 2 vols., en Jaén ${ }^{129}$. En el prólogo presenta el autor su obra como "herramienta de bufete", es decir, dirigida a seglares que necesiten desenvolverse en asuntos canónicos. El plan de la obra sigue puntualmente los libros y capítulos del Código, comentando los cánones principales. En la primera edición, como introducción, reproduce la exposición sobre "La potestad de la Iglesia" de Francisco de Vitoria. Del mismo autor son las siguientes obras: Cosas eclesiásticas, derecho procesaly penal de la Iglesia católica, 2 vols. (Madrid, 1920); El divorcio vincular y el dogma católico (Madrid, 1926) ${ }^{130}$.

Dalmacio Iglesias ${ }^{131}$ publicó en Barcelona sus Instituciones de derecho eclesiástico con arreglo al novísimo código del derecho canónico y según la teología, la apología y la filosofía e historia del derecho eclesiástico con inclusión de la disciplina eclesiástica española ${ }^{132}$. Obra editada en dos volúmenes, el primero de los cuales contiene una amplia introducción y la parte general ${ }^{133}$.

Como es sabido, Pedro Vidal colaboró con Franz Wernz en los volúmenes 5 y 6 (De indiciis ecclesiasticis e Iuspoenale Ecclesiae catholicae) del Ius Decretalium ${ }^{134}$, debido a las ocupaciones de este último como rector de la Universidad Gregoriana y, posteriormente, como superior de los jesuitas. Además actualizó esta magna obra según las disposiciones del Código canónico bajo el nuevo título de Ius Canonicum ad Codicis normam exactum, en siete volúmenes ${ }^{135}$. La obra sigue los libros del Código de Derecho Canónico, pero desglosando alguno de ellos en dos volúmenes. Así, el primer volumen coincide con el Libro I, de las normas generales. El Libro II está tratado en dos volúmenes por razones de extensión. Así, uno de ellos trata

moral (Madrid, 1918); y una obra más desarrollada sobre la anterior: Compendio de teología moral. Con arreglo al derecho natural, al nuevo Código canónico, y a la legislación civil, 2 vols. (Madrid, 1920).

${ }^{129}$ La tercera edición, de Madrid 1935, aparece corregida y aumentada con las nuevas disposiciones aparecidas hasta julio de 1934. Fue utilizada como libro de texto en diversas universidades y seminarios de España y América.

${ }^{130}$ Obra polémica, en la que defendía la potestad del papa de disolver matrimonios ratos y consumados. Fue por ello excomulgado en 1925 por Leopoldo Eijo y Garay, obispo de Madrid.

${ }^{131}$ Dalmacio Iglesias García (Santibáñez el Bajo [Cáceres], 05/12/1879 - Barcelona, 13/01/1933), licenciado en Derecho por la Universidad de Santiago de Compostela y doctor en Derecho por la Universidad Central. Diputado a Cortes por Gerona. Cfr. Enciclopedia universal ilustrada europeo-americana, vol. 28,1, pp. 939-940.

${ }^{132} \mathrm{Ni}$ en el ejemplar consultado ni en las referencias de la Biblioteca Nacional de España hay referencia precisa a las fechas de publicación, que pueden ser entre 1919 y 1920.

${ }^{133}$ Esta introducción incluye el concepto de derecho, nociones sobre filosofía cristiana del derecho y sobre la Escuela histórica y el positivismo, religión y libertad humana, concepto de Iglesia, organización de la jerarquía, luteranismo, anglicanismo, modernismo, etc. He tenido acceso solo a una versión incompleta del primer volumen, por lo que no puedo describir el contenido completo de la parte general y del segundo volumen.

${ }^{134}$ Wernz, Franz Xaver, Ius Decretalium ad usum praelectionum in scholis textus canonici sive Iuris decretalium (Romae, 1913-1914), V-VI.

${ }^{135}$ Editados en Roma, entre los años 1923 y 1938. 
la mayor parte del contenido del De personis ${ }^{136}$ y el otro sobre los religiosos y las asociaciones de laicos. El Libro III, De rebus, se trata en un solo volumen, pero dividido en dos tomos. En ellos se omite el derecho matrimonial, que es tratado por separado junto con sus aspectos procesales como volumen V. Finalmente, los Libros IV y V del Código son tratados en los volúmenes 6 y 7 (De processibus e Ius poenale ecclesiasticum) ${ }^{137}$.

Los volúmenes cuarto y quinto de la obra de José María Campos y Pulido, Legislación y jurisprudencia canónica novísima y disciplina particular de España. Exposición y comentario de las más recientes disposiciones dictadas en el pontificado de Su Santidad Pio Papa X [...], se publicaron con posterioridad a la promulgación del Código ${ }^{138}$. La obra no pretende ser un comentario completo ni definitivo, para lo que todavía es demasiado pronto, según opinión del autor. Por eso se centra principalmente en indicar los criterios que han presidido la elaboración del Código, la descripción de su forma y contenidos, el sentido en que mantiene o modifica la disciplina precedente y las más importantes novedades.

Campos y Pulido publicó también Derecho canónico. (Obra ajustada al Programa de oposiciones al Cuerpo de Aspirantes a la Judicatura y Ministerio fiscal, de 31 de enero de 1920) (Madrid, 1920). En su página 7 describe brevísimamente la necesidad de la reforma canónica y cómo se optó finalmente por la codificación en vez de por la promulgación de una nueva colección.

Miguel de Arquer publicó junto con Adriano Cance ${ }^{139}$, El Código de Derecho Canónico. Comentario completo y práctico de todos sus cánones para uso de eclesiásticos y hombres de leyes, 2 vols. (Barcelona, 1934). La obra renuncia a configurarse como manual para las clases y se plantea - sin renunciar por ello a conseguir un libro práctico-, como un completísimo comentario a todos y cada uno de los cánones del Código. De hecho, cada uno de los volúmenes llega casi a las mil páginas. En los comentarios se da referencia de las disposiciones concordadas, así como de las leyes dictadas por la entonces República española en relación con la Iglesia. Pensando también en el ámbito ibero americano, se comentan bajo esta perspectiva los cánones relativos a los seminarios, beneficios eclesiásticos y más de 600 cánones de derecho procesal. La obra sigue el orden de los libros del Código precedidos de una brevísima introducción general.

Eloy Montero ${ }^{140}$ dio a la luz una obra realmente peculiar en el ámbito español.

${ }^{136}$ Cabe destacar que, en este primer volumen, por razones pedagógicas el autor trata de modo conjunto de los oficios y beneficios, institución esta última que en el Código viene colocada en el Libro III, De rebus.

${ }^{137}$ Pienso que deben atribuirse a Vidal una serie de artículos sin firmar que aparecieron en La Civiltà Cattolica a lo largo de los años 1917 y 1918. La revista Apollinaris, 14 (1941) los atribuye, sin embargo, a Miguel de Arquer.

${ }^{138}$ Tomo 4: El nuevo Código de Derecho canónico. Estudio de las disposiciones que constituyen su articulado. Supromulgación. Reformas más importantes que ha introducido en la disciplina de la Iglesia Católica. Cánones $1^{\circ}$ al 725 - Libros $1^{\circ}$ y $2^{\circ}$ del mismo (Madrid, 1921); Tomo 5: El nuevo Código de Derecho Canónico (continuación). Estudio de las disposiciones que constituyen su articulado. Libro III del mismo - De rebus. Primera parte - De los sacramentos. (Cánones 726 al 1553) (Madrid, 1925).

${ }^{139}$ Adriano Cance, profesor del seminario mayor francés de Rodez.

${ }^{140}$ Eloy Montero y Gutiérrez (El Bodón [Salamanca], 12/12/1887 - Blascosancho [Ávila], 
Se trata de su Derecho canónico comparado. I: Fundamentos, preliminares y principios (Madrid, 1934). Supone un intento de ofrecer a los alumnos universitarios españoles un mejor conocimiento de la historia y organización de las Iglesias no católicas, donde la perspectiva histórica tiene gran peso en la exposición. Esta obra es realmente una remodelación de sus Instituciones de derecho canónico, 3 vols. (Madrid, 1929-1930). El primer volumen estaba dedicado a los fundamentos y preliminares y al primer Libro del Código; el segundo al derecho constitucional canónico -Libro II-; y el tercero al derecho administrativo y penal -Libros III y V-, quedando sin tratar el derecho procesal. En 1934, lo que hace en Derecho canónico comparado es añadir al primer volumen original una exposición de las diversas Iglesias, tanto la católica como la ortodoxa, protestante y anglicana, así como de las relaciones entre Iglesia y el Estado.

Fue un autor prolífico. Otras obras suyas directamente canónicas son: Programa de instituciones de derecho canónico (Valladolid, 1916); Tratado de matrimonio y las causas matrimoniales (Sevilla - Madrid, 1927); Casos prácticos de derecho canónico (Madrid, 1930); El matrimonio y las causas matrimoniales (Madrid, 1930); Derecho público eclesiástico y normas generales: Libro I del Código (Madrid, 1943); Manual de derecho canónico: obra consagrada especialmente a la República Argentina (Buenos Aires, 1950).

Manuel Giménez Fernández publicó unas Instituciones jurídicas en la Iglesia católica, 2 vols. (Madrid, 1940-1942). Concebida como obra elemental para estudiantes universitarios, no está estructurada siguiendo el orden de los Libros del Código, sino que trata el primer volumen de nociones preliminares, derecho público eclesiástico y nomología canónica, ocupándose el segundo del derecho patrimonial canónico, los procedimientos eclesiásticos y el derecho penal.

No se me ocurre mejor modo de acabar esta contribución sobre los canonistas españoles y la primera codificación canónica que hacerlo con la presentación de las principales obras de Eduardo Fernández Regatillo ${ }^{141}$, aunque algunas de las fechas

11/08/1972), realizó los estudios eclesiásticos en el seminario de Ciudad Rodrigo y completó sus estudios de Teología, Filosofía y Letras y Derecho en la Universidad de Salamanca. Doctor en Teología y en Derecho canónico por la Universidad Central. Profesor de Instituciones de Derecho canónico en la Facultad de Derecho de Valladolid y catedrático de esa asignatura por la Universidad de Sevilla. Posteriormente se trasladó a la Universidad Central, de la que fue decano de la Facultad de Derecho. Canónigo de las catedrales de Ciudad Rodrigo, Valladolid y provisor de la diócesis de Madrid-Alcalá. Miembro del Tribunal de la Rota Española. Cfr. Diccionario de catedráticos españoles de derecho, cit. (n. 25); Diccionario biográfico español, cit. (n. 6), XXXV, pp. 749750; Diccionario crítico de juristas españoles, portugueses y latinoamericanos, cit. (n. 25), II.1, pp. 162-163.

${ }^{141}$ Eduardo Fernández-Regatillo y Gómez-Pidal (Cortigueira-Suances [Cantabria], 26.04.1882 - Villagarcía de Campos [Valladolid], 05/11/1975), jesuita, realizó el doctorado en Teología en 1917 y en Derecho canónico en 1921 por la Universidad Gregoriana, tras lo cual se trasladó a la Universidad Pontificia de Comillas, de la que llegó a ser decano de la Facultad de Derecho canónico. Fue profesor de Ciencias canónicas tanto en la sede cántabra como en la madrileña. Miembro de la comisión pontificia que preparó el Concilio Vaticano II, asesor del Ministerio de Asuntos Exteriores y el de Justicia de España desde 1937 y consultor de la Nunciatura Apostólica y de la Comisión Pontificia para la revisión del Derecho Canónico desde 1966. Fue distinguido con la Cruz de Honor de San Raimundo de Peñafort y la Cruz de Alfonso X El Sabio. Cfr. Diccionario histórico de la Compañia de Jesús, cit. (n. 59), II, p. 1403; http://www. escritorescantabros.com/escritor/fernandez-regatillo-y-gomez-pidal-eduardo.html 
de publicación superen por poco el límite temporal del año 1940 autoimpuesto para este trabajo. Desde la perspectiva que nos ocupa, su obra más importante fue las Institutiones Iuris Canonici. I, Pars praeliminaris, normae generales, de personis. II, De rebus, de processibus, de delictis et poenis (Santander, 1941-1942). Se trata de una obra sobria pero precisa en el comentario de cada uno de los cánones del Código. En el lugar donde se debía tratar de los sacramentos (Parte primera del Libro III) el autor remite a su Ius Sacramentarium, cuya primera edición apareció en Santander en 1945, dividida en dos partes: De sacramentis in genere y De sacramentis in specie, incluyendo los sacramentales como título octavo, al igual que en el Código ${ }^{142}$. El Ius Sacramentarium conoció diversas ediciones, aportando los nuevos documentos producidos por la curia romana. En la edición de 1960 se incorpora el Concordato entre el Estado español y la Santa Sede de 1953, así como los reenvíos pertinentes a su obra Casos canónico - morales, 3 vols. (Santander, 1957-1960) ${ }^{143}$ que, en realidad, se trata de una nueva edición modificada y actualizada de Casos de derecho canónico, a la que me refiero más abajo.

Pero con anterioridad a estos títulos, el autor había ya publicado una obra compilatoria titulada Cuestiones canónicas de 'Sal Terrae'. Ordenadas y acomodadas al nuevo Código canónico, 2 vols. (Santander, 1927-1928). Allí se recogen las contribuciones que diversos autores (Justo Bona, Narciso del Castillo, Miguel Mostaza y el mismo Regatillo) hicieron en la sección Documental de la revista Sal Terrae, dirigida por los jesuitas y fundada en 1912. Regatillo recopiló estos artículos disponiéndoles según el orden codicial e, incluso, haciendo las modificaciones necesarias para adaptarlos a la nueva legislación. El primer volumen abarca los dos primeros Libros del Código y el segundo los restantes.

De similares características a la anterior son los tres volúmenes ya aludidos de Casos de derecho canónico. 1, Normas generales, Personas. 2, Simonía, Sacramentos. 3, Cosas, Procesos, Delitos, Penas (Santander, 1931 y 1935). Recoge las contribuciones publicadas en la sección Consultas de la revista Sal Terrae, así como otras muchas no publicadas. La originalidad de esta obra estriba en el carácter real de los casos presentados, procedentes de las consultas de juristas, canonistas, clérigos, párrocos y seglares. Como es de suponer, el contenido representa también un buen corolario de casos de conciencia.

Otra obra del autor, Interpretación y jurisprudencia del Código canónico (Santander, 1928), recoge disposiciones, instrucciones y respuestas de la Santa Sede relacionadas con el Derecho canónico desde el año 1917, así como ciertas disposiciones del poder civil español. La obra está dividida en dos partes (Interpretación y Jurisprudencia) y sigue el orden de los cánones ${ }^{144}$.

${ }^{142}$ La primera edición (Santander, 1945-1946) apareció en dos volúmenes, el primero de ellos con la parte general y los sacramentos del Bautismo, Confirmación, Eucaristía, Penitencia y Extremaunción; el segundo con el Orden, el Matrimonio y los sacramentales.

${ }^{143} \mathrm{El}$ primer volumen se llama Casos canónico; el cambio de título se produjo con el segundo volumen.

${ }^{144}$ La obra fue continuada con dos ampliaciones: Interpretación y jurisprudencia del Código canónico. Apéndice primero 1930. Apéndice segundo 1931 y 1932 (Santander, 1930 y 1933). Apareció 
Aguilar Jiménez, Juan, El nuevo Código de Derecho Canónico, en Revista Eclesiástica, 40 (1917), pp. 259, 261-265.

Álvarez de las Asturias, Nicolás, Decisión, decisiones y consecuencias de la primera codificación canónica: el caso de la idoneidad para recibir las órdenes sagradas, en Ius Canonicum, 115 (2018), pp. 37-68.

Álvarez Fernández, Jesús, Alphabetum Augustinianum, Institutum Historicum Augustinianum (http://iha.augustinians.net/index.php?page=biografie).

ArbeloA, Víctor Manuel, Los hombres que se adelantan a su tiempo: Jaime Torrubiano Ripoll (1879-1963), en El Ciervo, 230 (1973), 22, pp. 8-9.

- Aquella España católica (Salamanca, 1975).

Biographisch-Bibliographisches Kirchenlexikon, (Hamm, 1990).

Campos y Pulido, José María, Legislación y jurisprudencia canónica novísima y disciplina particular de España. Exposición y comentario de las más recientes disposiciones dictadas en el pontificado de Su Santidad Pio Papa X [...], 5 vols. (Madrid, 1921-1925).

-Derecho canónico. (Obra ajustada al Programa de oposiciones al Cuerpo de Aspirantes a la Judicatura y Ministerio fiscal, de 31 de enero de 1920) (Madrid, 1920).

-El nuevo Código de Derecho canónico y su próxima publicación, en Revista general de legislación y jurisprudencia, 130 (1917), pp. 374-387.

Cińurriz, María José, Elpensamiento científico de Pedro Lombardía (a través de su análisis por Javier Hervada), en Ius Canonicum, 118 (2019), pp. 665-696.

Cilleruelo, Lope, El Rvdmo. P. Maestro Fr. Eustasio Esteban, Prior General de la Orden de San Agustín (1860-1945) (Valladolid, 1955).

de Arquer, Miguel, El nuevo Código de Derecho Canónico, en Reseña Eclesiástica, 9 (1917), pp. 477-482.

De Arquer, Miguel; Cance, Adriano, El Código de Derecho Canónico. Comentario completo y práctico de todos sus cánones para uso de eclesiásticos y hombres de leyes, 2 vols. (Barcelona, 1934).

de Barcelona, Antonio María, El cardenal vives y Tutó de la Orden de Frailes Menores Capuchinos (Barcelona, 1916).

DE Echeverría, Lamberto, L'enseignement et les recherches de Droit canonique en Espagne, en L'Année Canonique, 5 (1957), pp. 125-137.

- La codificación del derecho canónico vista en España a finales del siglo XX, en Apollinaris, 33 (1960), pp. 327-341.

De Langasco, Agatángel, El cardenal Vives y la codificación del derecho canónico, en Revista Española de Derecho Canónico, 10 (1955), pp. 457-475.

De Montagut, J. Evangelista, El cardenal vives canonista y su labor al frente de la Congregación de Religiosos, en Estudios Franciscanos, $\mathrm{n}^{\circ}$ especial (1913), pp. 65-74.

de Palau, Camilo, El Código civily el Código eclesiástico: La Luz Canónica, 1/1 (1891-1892), pp. 100-108, 163-172, 294-313, 348-361, 423-436, 570-584, 632-647, 704-715, 766-777; ibíd., $1 / 2$ (1893), pp. 51-61, 108-117, 173-183, 237-247, 295-303, 363371, 414-426, 544-551, 624-630, 684-692, 739-751.

De s. Luis Gonzaga, Amalio, El Rvdo. P. Joaquin de S. Simón Stock, en El Monte Carmelo, 30 (1926), pp. 318-322.

también una versión latina: Interpretatio et Iurisprudentia Codicis Iuris Canonici (Santander, 1949), que conoció hasta la tercera edición de 1953. 
-, Analecta Ordinis Carmelitarum Excalceatorum, 1 (1926), pp. 222-224.

Diccionari d'bistoria eclesiastica de Catalunya (Barcelona, 1998-2001).

Diccionario biográfico español, Real Academia de la Historia (Madrid, 2009-2013).

Diccionario crítico de juristas españoles, portugueses y latinoamericanos (Hispánicos, brasileños, Quebequenses y restantes francófonos) (Zaragoza - Barcelona, 2005-2006).

Diccionario de catedráticos españoles de derecho (1847-1943) [en línea]. Universidad Carlos III de Madrid. Instituto Figuerola de Historia y Ciencias Sociales: http://www. uc3m.es/diccionariodecatedraticos.

Diccionario de historia eclesiástica de España, Consejo Superior de Investigaciones Científicas (Madrid, 1972-1987).

Diccionario histórico de la Compañia de Jesús. Biográfico-temático, (Roma-Madrid, 2001).

Dieguez, Alejandro Mario, Carte Pio X. Scritti, omelie, conferenze e lettere di Giuseppe Santo. Cenni storici, inventario e appendice documentaria (Città del Vaticano, 2010).

—L'archivio particolare di Pio X. Cenni storici e inventario (Città del Vaticano, 2003).

Dieguez, Alejandro Mario; Pagano, Sergio, Le carte del "Sacro tavolo". Aspetti del pontificato di Pio X dai documenti del suo archivio privato, 2 vols. (Città del Vaticano, 2006).

Enciclopedia cattolica (Città del Vaticano, 1949-1954).

Enciclopedia universal ilustrada europeo-americana (Madrid, 1930).

FANTAPPIÈ, Carlo, Chiesa romana e modernità giuridica, II: Il Codex iruis canonici (1917) (Milano, 2008).

—Dal paradigma canonistico classico al paradigma codificatorio, en BAURA, Eduardo; ÁlvarEZ DE LAs Asturias, Nicolás; Sol, Thierry (a cura di), La codificażione e il diritto nella Chiesa (Milano, 2017), pp. 3-34.

—El Código de 1917 en la Historia del derecho de la Iglesia, en Anuario de Derecho Canónico, 7 (abril 2018), pp. 41-55.

- Per un cambio di paradigma: Diritto canonico, teologia e riforme nella Chiesa (Bologna, 2019), pp. 36-71.

Fernández Valbuena, Ramiro, La Luz Canónica, 2/1 (1899-1900), pp. 20-26.

Ferreres, Juan Bautista, La codificación del derecho canónico decretada por Pío X, en Razón y Fe, 9 (1904), pp. 365-369.

-Los esponsales y el matrimonio según la novísima disciplina. Comentario canónico-moral sobre el decreto 'Ne Temere' (5a ed., Madrid, 1911).

_El Código canónico. Monumento insigne de Pío X y Benedicto XV, en Razón y Fe, 48 (1917), pp. 502-511.

-Instituciones canónicas con arreglo al novísimo código de Pío X $[. .$.$] y a las prescripciones de la$ disciplina española y de la América latina, 2 vols. (Madrid, 1917).

-Derecho sacramental y penal especial. Con arreglo al novísimo Código de Pio X, promulgado por Benedicto XV, a las declaraciones subsiguientes de la Santa Sede y a las prescripciones de la disciplina española y de la América Latina (Barcelona, 1918).

- Compendium theologiae moralis ad norman novissimi codicis canonici, 2 vols. (Barcinone, 1918-1919) = Compendio de teología moral según la norma del novísimo código canónico, 2 vols. (Barcelona 1920).

-Epitome compendii theologiae moralis (2a ed., Barcinone, 1918) = Epitome del compendio de teología moral (Barcelona, 1921).

—Las religiosas según la disciplina vigente $[. .$.$] comentarios canónico-morales \left(3^{\mathrm{a}}\right.$ ed., Madrid, 1908).

—Las religiosas según la disciplina del nuevo Código de Derecho Canónico. Comentarios canónicomorales (Madrid, 1920). 
Fuster, Fernando, en Razón y Fe, 55 (1919), pp. 248-251.

GIMÉNEZ y FernándeZ, Manuel, Instituciones jurídicas en la Iglesia católica, 2 vols. (Madrid, 1940-1942).

Gómez-IGLESIAS, Valentín, La ricezione del codice del 1917 nella dottrina e nell'insegnamento, en Baura, Eduardo; Álvarez de las Asturias, Nicolás; Sol, Thierry (a cura di), La codificazione e il diritto nella Chiesa (Milano, 2017), pp. 72-119.

- De la centralidad de la ley al primado de la persona en el Derecho de la Iglesia. Historia y perspectivas canónicas en el centenario del Código de 1917, en Ius Canonicum, 114 (2017), pp. 495-568.

Goyeneche, Siervo, Balance de la Codificación, en Estudios de Deusto, 17 (1961), pp. 97-118.

Gurr, Jean Pierre; Ferreres, Juan Bautista, Casus conscientiae. Novis casibus aucti, novissi codici canonico, dispositionibus iuris hispani ac lusitani, decretis concilii plenarii Americae Latinae necnon conc. prov. Manilani earumdemque regionum legibus peculiaribus, 2 vols. (Barcinone, 1920-1921).

Herce, Cipriano, La reforma del derecho canónico, en La Luz Canónica, $1 / 1$ (1891-1892), pp. 5-14, 74-79, 131-135, 193-199, 261-268, 333-337, 454-458.

IgLESIAS, Dalmacio, Instituciones de derecho eclesiástico con arreglo al novísimo código del derecho canónico y según la teología, la apología y la filosofía e historia del derecho eclesiástico con inclusión de la disciplina eclesiástica española, 2 vols. (Barcelona, 1919).

Jacquemet, G. (dir.), Catholicisme. Hier, aujourd'hui, demain, VIII, coll. 1236-1238.

Jorde, Elviro, Catálogo bio-bibliográfico de los religiosos agustinos de la Provincia del Santísimo Nombre de Jesús de las Islas Filipinas desde su fundación hasta nuestros días (Manila, 1901).

Lazcano, Rafael, Generales de la Orden de San Agustin. Biografía - Documentación - Retratos (= Studia Augustiniana Historia 10), Institutum Historicum Augustinianum (Roma, 1995), pp. 193-204.

Lizarraga, José Javier, Centenario del reconocimiento de los Agustinos Recoletos como orden religiosa (1912-2012). El breve "Religiosas Familias" (16 septiembre 1912), en Recollectio, 36 (2013), pp. 19-147.

Llaquet de Entrambasaguas, José Luis, Incidencia del CIC de 1917 en el derecho estataly concordatario español, en MARTín, María del Mar (ed.), Entidades eclesiásticas y derechos de los Estados. Actas del II Simposio Internacional de Derecho concordatario. Almería, 9-11 de noviembre de 2005 (Granada, 2006), pp. 535-541.

- La correspondencia entre la Nunciatura española y la Secretaría de Estado vaticana con ocasión del pase regio del CIC de 1917 en España, en CaTTANEO, Arturo (curatore), L'eredità giuridica di san Pio X (Venezia, 2006), pp. 217-221.

- Controversias en torno al derecho supletorio catalán con ocasión de la promulgación del código canónico de 1917, en Revista de Dret Històric Català, 2 (2002), pp. 171-201.

—La Discusión doctrinal acerca del código canónico de 1917 como ley del reino de España, en Revista de Dret Històric Català, 14 (2015), pp. 323-336.

LLobell, Joaquín; De León, Enrique; Navarrete, Jesús, Il libro "De processibus" nella codificazione del 1917. Studi e documenti. 1, Cenni storici sulla codificazione "de iudiciis in genere", il processo contenzioso ordinario e sommario, il processo di nullità del matrimonio (Milano, 1999).

Lombardía, Pedro, La sistemática del Codex y su posible adaptación, en Estudios de Deusto, 17 (1961), pp. 213-237.

López Ortiz, José, en Código de Derecho Canónico (Madrid, 1945), pp. xvii-xxxvii.

Manjón y Manjón, Andrés, Derecho Eclesiástico General y Español (4ª ed., Granada, 1913), I. 
Mansi, Joannes Dominicus (ed.), Sacrorum Conciliorum nova et amplissima collectio (Graz, 1960-1962).

MANTECÓN SANCHO, Joaquín, La enseñanza del derecho canónico en las universidades públicas españolas, en Kritische Zeitschrift für überkonfessionelles Kirchenrecht, 3 (2016) (consultado online: http://www.eumed.net/rev/rcdcp/03/jms.html).

Marín Cano, Alfredo, El Canónigo Dr. D. Diego Tortosa y Nicolás (1877-1947) (Murcia, 2014).

MAROTO, Felipe, Institutiones iuris canonici ad normam novi codicis (Madrid, 1918-1919) = Instituciones de derecho canónico de conformidad con el nuevo Código. Seguida de las Lecciones de disciplina eclesiástica de España (Madrid, 1919).

MERRY Del VAL, Rafael, Impressioni e ricordi (Padova, 1925).

- Memorias del Papa Pio X (Madrid, 1946).

Montero, Eloy, Programa de instituciones de derecho canónico (Valladolid, 1916).

— Tratado de matrimonio y las causas matrimoniales (Sevilla - Madrid, 1927).

-Instituciones de derecho canónico, 3 vols. (Madrid, 1929-1930).

- Casos prácticos de derecho canónico (Madrid, 1930).

—El matrimonio y las causas matrimoniales (Madrid, 1930).

—Derecho canónico comparado, I: Fundamentos, preliminares y principios (Madrid, 1934).

—Derecho público eclesiástico y normas generales: Libro I del Código (Madrid, 1943).

- Manual de derecho canónico: obra consagrada especialmente a la República Argentina (Buenos Aires, 1950).

Mostaza, Miguel, El nuevo Código de Derecho Canónico promulgado por Benedicto XV, en Sal Terrae, 6 (1917), pp. 540-547, 617-627.

—Derechos y deberes de los párrocos según el nuevo Código, en Sal Terrae, 7 (1918), pp. 143-146.

-Derechos y deberes de los eclesiásticos según el nuevo Código, en Ibid., pp. 222-227.

-Nueva disciplina matrimonial en el actual Código canónico, en Ibid., pp. 365-372.

—Privilegios más usuales de los Ordinarios y de los curas en el nuevo Código, en Ibid., pp. 526-532.

—Censuras 'latae sententiae’ según el nuevo Código, en Ibid., pp. 601-608, 769-782, 919-932.

Muniz Pablos, Tomás, Derecho parroquial según el "Codex Iuris Canonici" (1ª ed., MadridSevilla, 1918).

Navarro Valls, Rafael, La enseñanza del derecho canónico en las Facultades de Derecho españolas, en Anuario de Derecho Eclesiástico del Estado, 1 (1985), pp. 55-72.

Noval, José, El Código de derecho canónico, en La Ciencia Tomista, 16 (1917), pp. 141-172.

—Codificationis Juris Canonici. Recensio historico-apologetica et Codicis Piano-Benedictini, notilia generalis doctrina ad studium novi Codicis Canonici propaedeutica (Romae, 1918).

-Commentarium Codicis Iuris Canonici. Liber IV, De processibus, 3 vols. (Augustae Taurinorum - Romae, 1920).

Pedret Casado, Paulino, La evolución de la enseñanza del derecho canónico en España, en Boletim da Faculdade de Direito da Universidade de Coimbra, 22 (1946), pp. 364-380.

Pérez Alhama, Juan, El derecho canónico en la Universidad española, en Ius Canonicum, 4 (1964), pp. 371-412.

Postíus y SALA, Juan, El Código canónico aplicado a España en forma de Instituciones (5 $5^{\mathrm{a}} \mathrm{ed}$, Madrid, 1926).

—El Código canónico o descripción y resumen del Codex Iuris Canonici (Madrid, 1918).

-Codex Juris Canonici, en Ilustración del Clero, 11 (1917), pp. 217-225, 233-240, 249-258, 265-273, 281-284, 297-301, 313-317, 329-333.

—El código canónico aplicado a España, en Ilustración del Clero, 12 (1918), pp. 255-256, 278-280, 297-298. 
Pujadas, Tomás Luis, El Padre Postius: un hombre para la Iglesia (Barcelona, 1981).

Ramos Pérez, Herminio, Zamoranos de ayery de siempre, (Zamora, 2015): http://www. laopiniondezamora.es/opinion/2009/08/07/cipriano-herce-castro/375947.html

Rayón Ballesteros, María Concepción, Aproximación a la historia de la enseñanza del derecho en nuestro país, en Anuario Jurídico y Económico Escurialense, 43 (2010), pp. 215-236.

Regatillo, Eduardo F., La enseñanza del derecho canónico, en Él mismo, Cuestiones canónicas de "Sal Terrae". Ordenadas y acomodadas al nuevo código canónico (Santander 1927), I, pp. 5-20.

—Interpretación y jurisprudencia del Código canónico (Santander, 1928).

-Interpretación y jurisprudencia del Código canónico. Apéndice primero 1930. Apéndice segundo 1931 y 1932 (Santander, 1930 y 1933) = Interpretatio et Iurisprudentia Codicis Iuris Canonici (Santander, 1949).

_Institutiones Iuris Canonici. I: Pars praeliminaris, normae generales, de personis. II : De rebus, de processibus, de delictis et poenis (Santander, 1941-1942).

-Derecho parroquial (1 ${ }^{\text {a }}$ ed., Santander, 1951).

- Casos canónico - morales, 3 vols. (Santander, 1957-1960).

-Ius Sacramentarium ( $3^{\mathrm{a}}$ ed., Santander, 1960).

Roberti, Franciscus, Codicis Iuris Canonici schemata De Processibus, en Acta Congressus Iuridici Internationalis (Romae, 1937), IV.

Salinas Araneda, Carlos, La codificación del derecho canónico de 1917, en Revista de Derecho de la Pontificia Universidad Católica de Valparaíso, 30 (2008), pp. 311-356.

SANTAMARía, Federico, Esponsales, matrimonio, divorcios y pleitos matrimoniales, con arreglo al nuevo Código Canónico y a la legislación civil, para utilidad de abogados y sacerdotes. Variaciones del nuevo Código Canónico en la teología moral (Madrid, 1918).

—Comentarios al Código Canónico, 3 vols. (Madrid, 1919-1922).

- Compendio de teología moral. Con arreglo al derecho natural, al nuevo Código canónico, y a la legislación civil, 2 vols. (Madrid, 1920).

-Comentarios al Código Canónico, 3 vols. (Madrid, 1919-1922).

Serra de Manresa, Valentí, El Cardenal Vives $i$ Tutó (1854-1913). Aspectes biogräfics $i$ projecció eclesial, en Analecta Sacra Tarraconensia, 77 (2004), pp. 233-272.

—El capuchino José de Calasanz de Llavaneres, cardenal Vives y Tutó (1854-1913). Su actuación durante los pontificados de León XIII y Pio X, en Archivum Historiae Pontificiae, 44 (2006), pp. 173-205.

TARQUINI, Camillo, Instituciones de derecho público eclesiástico seguidas de una disertación sobre el pase regio, del Syllabus y la constitución 'Pastor Aeternus' del concilio vaticano (Granada, 1881).

Torralba y García de Soria, Fernando, La codificación del derecho canónico (Sevilla, 1906).

- Sermón panegirico del Gran Apóstol San Pablo, Patrono de la muy Noble y Muy Leal ciudad de Ecija, predicado el día 25 de enero de 1958, día de su conversión, en la Iglesia de Santo Domingo de la misma ciudad (Écija, 1958).

Torrubiano Ripoll, Jaime, Novísimas instituciones de derecho canónico. Acomodadas al nuevo 'Código' ordenado por S. S. el Papa Pí X y promulgado por la Santidad de Benedicto XV ( $3^{\text {a }}$ ed., Madrid, 1935).

- Cosas eclesiásticas, derecho procesal y penal de la Iglesia católica, 2 vols. (Madrid, 1920).

-El divorcio vincular y el dogma católico (Madrid, 1926).

Tortosa, Diego, El nuevo código de derecho canónico, en Revista General de Legislación y Jurisprudencia, 131 (1917), pp. 399-412; 132 (1918), pp. 68-89, 361-379; 133 (1918), 
pp. 99-117, 239-257; 134 (1919), pp. 15-27; 135 (1919), pp. 110-130; 137 (1920), pp. 116-138; 138 (1921), pp. 309-324.

Valentí, J. I., El nuevo Código canónico y una obra importante de derecho, en Revista Eclesiástica, 42 (1918), pp. 549-556.

Vázquez García-Peñuela, José María, La publicación en España del decreto 'Ne temere' como ley del Reino, en Cattaneo, Arturo (curatore), L'eredità giuridica di san Pio X (Venezia, 2006), pp. 323-334.

VIDAL, Pedro, Ius Canonicum ad Codicis normam exactum, 7 vols. (Romae, 1923-1938).

-Il nuovo Codice di diritto canonico, en La Civiltà Cattolica, 68, vol. 2 (1917), pp. 545-559.

VILLADA, P., El Código de Derecho Canónico en las Cortes españolas, en Razón y Fe, 51 (1918), pp. 413-424.

Villaplana, J., Novísimo derecho canónico, en Revista Eclesiástica, 41 (1917), pp. 49-57.

Wernz, Franz Xaver, Ius Decretalium ad usum praelectionum in scholis textus canonici sive Iuris decretalium (Romae, 1913-1914), V-VI. 